\title{
On Warm and Moist Air Intrusions into Winter Arctic
}

\section{2}

Cheng You ${ }^{1}$, Michael Tjernström ${ }^{1}$, Abhay Devasthale ${ }^{2}$

${ }^{1}$ Department of Meteorology \& Bolin Centre for Climate Research, Stockholm University, Stockholm, Sweden.

${ }^{2}$ Remote Sensing Unit, Research and Development Department, Swedish Meteorological and Hydrological Institute, Norrköping, Sweden.

Correspondence to: Cheng You (cheng.you@ misu.su.se)

Abstract. In this study, warm and moist air intrusions (WaMAI) over the Arctic Ocean sectors of Barents, Kara, Laptev, East Siberian, Chukchi and Beaufort Seas in recent 40 winters (from 1979 to 2018) are identified from ERA5 reanalysis using both Eulerian and Lagrangian views. The analysis shows that WaMAIs, fuelled by Arctic blockings, causes a relative surface warming and hence a sea ice reduction by exerting positive anomalies of net thermal irradiances and turbulent fluxes to the surface. Over Arctic Ocean sectors with land-locked sea ice in winter, such as Laptev, East Siberian, Chukchi and Beaufort Seas, total surface energy budget is dominated by net thermal irradiance. From a Lagrangian perspective, total water path (TWP) increases linearly with the downstream distance from the sea ice edge over the completely ice-covered sectors, inducing almost linearly increasing net thermal irradiance and total surface energy-budget. However, over the Barents Sea, with an open ocean to the south, total net surface energy-budget is dominated by the surface turbulent flux. With the energy in the warm-and-moist air continuously transported to the surface, net surface turbulent flux gradually decreases with distance, especially within the first 2 degrees north of the ice edge, inducing a decreasing but still positive total surface energy budget. The boundary-layer energy-budget patterns over the Barents Sea can be categorized into three classes: radiation-dominated, turbulence-dominated and turbulence-dominated with cold dome, comprising about $52 \%, 40 \%$ and $8 \%$ of all WaMAIs, respectively. Statistically, turbulence-dominated cases with or without cold dome occur along with one order of magnitude larger large-scale subsidence than the radiationdominated cases. For the turbulence-dominated category, larger turbulent fluxes are exerted to the surface, probably because of stronger wind shear. In radiation-dominated WaMAIs, stratocumulus develops more strongly and triggers intensive cloud-top radiative cooling and related buoyant mixing that extends from cloud top to the surface, inducing a thicker well-mixed layer under the cloud. With the existence of cold dome, fewer liquid water clouds were formed and less or even negative turbulent fluxes could reach the surface.

Keywords: Arctic climate, Stratocumulus, Trajectories, Warm and moist air intrusions

\section{Introduction}

In recent decades, rapidly intensified Arctic warming has been observed (Cohen et al., 2014; Francis and Vavrus, 2012; Graversen et al., 2008), which has become known as Arctic amplification (Serreze and Francis 2006). Accompanying this warming has been a dramatic melting of Arctic sea ice (Simmonds, 2015). Particularly over the Barents Sea, a rapid warming rate, as well as a remarkable sea ice decrease, is found, which may have impacts on the extreme cold winter in Eurasia (Kim et al., 2014; Kim and Son, 2016; Mori et al., 2014; Overland et al., 2011; Petoukhov and Semenov, 2010; Tang et al., 2013). 
37 Arctic amplification is likely a consequence of many contributing processes and a detailed attribution to different

38 factors is yet to be performed. The most commonly implied mechanism is the so-called albedo feedback, based on the consideration that open water absorbs considerably more solar radiations than sea ice, which would accelerate Arctic warming (Kim et al., 2019). However, Arctic amplification is the strongest in winter, when the sun is mostly absent and the albedo by definition plays no role at all. This suggests that atmospheric energy transport by warm-and-moist intrusions (WaMAI) may play an important role for Arctic amplification, especially in winter. The positive trend in number of winter WaMAIs can statistically explain a substantial part of the surface air temperature and sea-ice concentration trends in the Barents Sea (Woods and Caballero, 2016).

Most of these studies deal with winter and focus either on the dynamical mechanisms resulting in WaMAIs, or on the effects of WaMAIs on the Arctic climate system conducted from an Eulerian perspective by retrieving composite mean of WaMAIs properties (Liu et al., 2018), or calculating regressions between different metrics (Gong and Luo, 2017). In recent years it has been increasingly argued that the concept of Lagrangian air mass transformation is necessary for studying WaMAIs (Pithan et al. 2018, 2020; Komatsu et al. 2018, Tjernström et al. 2019). A method using trajectories to analyze WaMAIs from a Lagrangian perspective was designed by You et al. (2020) and tested on a summer WaMAI event described in Tjernström et al. (2015). This method was utilized to build a climatology of summer WaMAIs (You et al., 2021). In this paper, we use this method to explore winter WaMAIs over several sectors of the Arctic Oceans: the Barents, Kara, Laptev, East Siberian, Chukchi and Beaufort Seas. Over the Barents Sea, sea ice concentration is decreasing and the near-surface atmosphere south of the ice edge is heated by comparatively warm open water. In contrast, for the Laptev, East Siberian, Chukchi and Beaufort Seas, the ocean surface is almost completely frozen to the coast and the insulation effect by sea ice suppresses heat transfer between ocean and atmosphere. We will attempt understanding the distinctions between the ocean sector with open water and those with land-locked sea ice by comparing surface and boundary-layer energy-budget from both Eulerian and Lagrangian perspectives.

\section{Data and method}

\subsection{Data}

62 We use the latest reanalysis from European Centre for Medium-Range Weather Forecast (ECMWF), ERA5

63 (Hersbach et al., 2020) in this study. For the detection and Eulerian analysis of WaMAIs in recent 40 winters 64 (DJF from 1979 to 2018), we use the reanalysis dataset at a 6-hourly temporal and $\mathbf{0 . 7 5}{ }^{\circ}$ horizontal resolution. This includes the vertically integrated northward water vapor flux $\left(\boldsymbol{f}_{\boldsymbol{w}}\right)$, sea ice concentration (SIC), 500-hPa geopotential height $\left(\mathrm{GH}_{500}\right), 2 \mathrm{~m}$ air temperature $\left(\boldsymbol{T}_{\mathbf{2 m}}\right), 850$-hPa temperature $\left(\boldsymbol{T}_{\mathbf{8 5 0}}\right)$, total water path (TWP), liquid water path (LWP), ice water path (IWP) and precipitation rate (PRCP). For the Lagrangian analysis we also use ERA5 3D wind field at a 6-hourly resolution for the air-mass trajectories calculations during WaMAIs, in the same way as described in You et al. $(2020,2021)$. For this we additionally use forecast data from ERA5 at the higher temporal resolution (1-hourly). This includes surface net solar $\left(F_{s w}\right)$ and thermal $\left(F_{l w}\right)$ irradiances, the surface sensible $\left(F_{s h}\right)$ and latent heat fluxes $\left(F_{l h}\right)$, as well as the 1-hourly temperature tendencies due to different model physics extracted at model levels. 
Ocean are sparse, especially in winter, and the loss of all visible wavelengths in passive remote sensing in winter makes the satellite products less trustworthy. However, it would be not possible to analyze air mass transformation climatologically on the energy-budgets along the trajectories of winter WaMAIs in any other way than relying on reanalysis. Here, we alleviate uncertainty in two ways; first, by averaging over a large number of cases and second, by considering anomalies rather than actual mean values. Avoiding single case studies reduces random errors, while considering anomalies reduces systematic errors.

\subsection{WaMAI Detection}

We identify WaMAIs by analyzing the vertically integrated northward moisture flux, $f_{\mathrm{w}}$, over the ocean sectors of Barents, Kara, Laptev, East Siberian, Chukchi and Beaufort Seas (Figure 1) separately. Among these sectors, winter SIC only varies substantially over the years in the Barents and Kara Seas. North of $80^{\circ} \mathrm{N}$ in the Barents Sea, SIC has a statistically significant correlation with $f_{\mathrm{w}}$ (Figure $2 \mathrm{a}$ ); locations that pass a $\mathrm{p}<0.05$ Student's ttest (stippled in Figure 2a) are considered the sensitive region. For the remaining sectors, all sea ice covered locations are considered sensitive regions since they do not display winter trends in SIC. The mean $f_{\mathrm{w}}$ over the sensitive regions, $\overline{f_{w}}$, is approximately normally distributed (Figure $2 \mathrm{~b}$ and $\mathrm{d}$ ). we define a WaMAIs as when $\overline{f_{w}}>$ 0 (red lines in Figure 2c and e) and their maxima larger than the 95-percentile, while portions of WaMAIs when $\overline{f_{w}}$ is larger than the 95-percentile are considered extreme moist intrusions (EMIs; blue lines in Figure 2c and e).

Similar as You et al.(2021, 2020), ensembles of two day forward and backward trajectories at different altitudes are calculated for each WaMAI over all ocean basins, using the trajectory algorithm from Woods et al. (2013). The launch points are taken where $T_{850}$ at $75^{\circ} \mathrm{N}$ is the largest (blue lines in figure $2 \mathrm{a} ; 80^{\circ} \mathrm{N}$ for the Barents Sea, red line in figure 2a) and forward (backward) trajectories are also terminated where they start to track southward (northward). Hence, we only capture the part of each trajectory that continuously tracks northwards. Finally, the terminal points of selected trajectories have to be at least $5^{\circ}$ north of the sea-ice edge. Trajectories are calculated at several different heights, every $100 \mathrm{~m}$, from $300 \mathrm{~m}$ to $800 \mathrm{~m}$ and vertical profiles of the various variables are then extracted from ERA5, from the surface to $2 \mathrm{~km}$, by interpolation in time and space along each of these trajectories. The final vertical cross-section for each WaMAI is the ensemble average of the results along all trajectories for that WaMAI. For the 40 winters in this study 87 (131) WaMAIs are detected over the ocean sectors with open ocean (land-locked sea ice) for a total of 218 WaMAIs.

\subsection{Energy Budgets}

As shown in Eq. 1, total surface energy-budget $\left(F_{\text {total }}\right)$ is contributed by surface net solar irradiance $\left(F_{s w}\right)$, surface net thermal irradiance $\left(F_{l w}\right)$, surface turbulent sensible heat fluxes $\left(F_{s h}\right)$ and surface turbulent latent heat fluxes $\left(F_{l h}\right)$. Note that all surface net energy fluxes contributing to a surface warming are considered positive. Individual terms in Eq. 1 are also interpolated from ERA5 at each 0.5-degree interval in latitude along the trajectories.

$$
F_{\text {total }}=F_{s w}+F_{l w}+F_{s h}+F_{l h}(1)
$$

We also evaluate the cloud longwave radiative effects (CRE) $\left(F_{l w_{-} C R E}=F_{l w_{-} a l l_{-} s k y}-F_{l w_{-} c l e a r_{-} s k y}\right)$, using the same method. $F_{l w_{-} a l l_{-} s k y}$ is the surface net thermal irradiance, considering the actual clouds presence, while $F_{l w_{-} \text {clear_sky }}$ is clear-sky counterpart, assuming clouds were not present. 
111 For the atmospheric energy budget calculations, we also extract the temperature tendencies due to different model

112 physics from ERA5, where we can resolve all terms in the thermal equation (Eq. 2). As shown in Eq. 2, the total

113 temperature tendency $T_{t}$ of an air-mass in a WaMAI is contributed by heating/cooling from the divergence of

114 shortwave irradiance $\left(\frac{\partial T}{\partial t_{S W}}\right)$, longwave irradiance $\left(\frac{\partial T}{\partial t}{ }_{l W}\right)$ and vertical turbulent heat flux $\left(\frac{\partial T}{\partial t}_{T H}\right)$ and the latent heat

115 of condensation in cloud formation $\left(\frac{\partial T}{\partial t_{L H}}\right)$. In a Lagrangian view, the advection tendencies are by definition zero,

116 while in a Eulerian view, the total tendencies would additionally be balanced by temperature advection. All these

117 terms are also interpolated along the trajectories as previously discussed (also see You et al. 2020, 2021).

$$
T_{t}={\frac{\partial T}{\partial t_{S W}}}+{\frac{\partial T}{\partial t_{l W}}}_{l t_{L H}}+{\frac{\partial T}{\partial t_{T H}}}_{{ }_{T}}
$$

Note that while the surface energy budget depends on the surface fluxes, the atmospheric energy budget depends in the vertical gradient of fluxes.

\section{Results}

\subsection{Large-scale Features}

EMIs were identified in the Arctic ocean basins of Barents, Kara, Laptev, East Siberian, Chukchi and Beaufort. Figure 3 (4) shows the composite of all EMIs over the Barents (Beaufort) Sea, representing the large-scale features of winter EMIs over ocean sectors with open ocean (land-locked sea ice). Both figure 3a and 4a show one pair of negative and positive $\mathrm{GH}_{500}$ anomalies with a large geopotential height gradient in between, generating an intensive $f_{w}$ anomaly directed into the Arctic (Figure 3c, 4c), enhancing temperature advection (Figure 3b, 4b) and cloud formation (Figure 3d, 4d), consistent with previous studies (Tjernström et al. 2015; Overland and Wang 2016; Gong and Luo 2017; Johansson et al., 2017; Sedlar and Tjernström 2017; Messori et al. 2018; Cox et al. 2019; You et al., 2021). Unlike over the Barents Sea, where the TWP anomaly is dominated by LWP (Figure 4d and 4e), TWP over the Beaufort Sea is dominated by IWP. These features in the $\mathrm{GH}_{500}, T_{850}$ and TWP anomalies are also found in all other ocean basins.

As warm and moist air is advected into the Arctic over the Barents Sea, it interacts with the cool ice surface through turbulence and radiation, enforcing positive $F_{s h}, F_{l h}$ and $F_{l w}$ anomalies at the surface (Figure 5c, $5 \mathrm{~d}$ and $5 \mathrm{e}$ ). The $F_{s h}$ anomaly reaches $>60 \mathrm{~W} \mathrm{~m}^{-2}$ over open water near the Norwegian coast, tapering off northward over the ice all the way to the pole. The pattern of $F_{l h}$ anomaly is similar to that of $F_{s h}$ south of $80^{\circ} \mathrm{N}$, but decreases to nearly zero over the sea ice north of $80^{\circ} \mathrm{N}$. Positive LWP and IWP anomalies in figure $3 \mathrm{~d}$ and $3 \mathrm{e}$, extending from the coast to the north pole along the path of the EMIs, also affects the surface energy-budget with a positive $F_{l w}$ anomaly (Figure 5c). This relation between $F_{l w}$ anomaly and winter EMIs over the Barents Sea is also discussed in other climatological analyses (Gong et al., 2017; Gong and Luo, 2017). In total, these anomalies in the surface-energy fluxes sum up to a positive $F_{\text {total }}$ anomaly, inducing decreased SIC (Figure $5 b$ ).

Similar surface energy-budget pattern is also found over the Beaufort Sea (Figure 6) but with some differences. The anomaly in $F_{\text {total }}$ over the Barents Sea is dominated by $F_{\text {sh }}$, while $F_{\text {total }}$ anomaly over the Beaufort Sea is dominated by $F_{l w}$. The magnitudes of $F_{s h}, F_{l h}$ and $F_{\text {total }}$ anomalies over the Beaufort Sea are less half the magnitude of those over the Barents Sea, especially south of $80^{\circ} \mathrm{N}$ and hence induce four times less SIC decrease. As EMIs occur over the Beaufort Sea, positive $F_{s h}, F_{l h}, F_{\text {total }}, F_{l w}$, LWP and IWP anomalies and negative SIC 
anomaly is found. However, negative $F_{s h}, F_{l h}, F_{t o t a l}, F_{l w}$, LWP and IWP anomalies and positive SIC anomalies could also be found over the Barents Sea sector, while some WaMAIs from the Beaufort Sea pass through the pole and become cold spells over the Barents Sea (Figure 4 and 6).

Table 1 summarizes the averaged surface energy-budgets over sea ice across the six basins. Except for the Barents Sea, $F_{l w}$ anomalies are almost twice larger than $F_{s h}$ anomalies. Since $F_{s w}$ anomalies can be ignored in winter, the $F_{l w}$ anomalies dominate $F_{\text {total }}$. However, over the Barents Sea, $F_{s h}$ anomalies are almost twice larger than $F_{l w}$ anomalies and contributes to more than $50 \%$ of $F_{\text {total }}$ anomalies. Over the Barents and Chukchi Sea, positive $F_{s h}$ anomalies are statistically significant, which is not the case for any of the other sectors. Except for the Laptev Sea, positive $F_{\text {total }}$ and $F_{l w}$ anomalies are statistically significant.

The composites of large-scale pattern discussed above are extracted from the stronger EMI events to generate a clear signal, however, these may not necessarily represent the general pattern of all WaMAIs. Therefore, linear regressions of daily averaged $\mathrm{GH}, T_{850}, \mathrm{SIC}, F_{t o t a l}, F_{s h}, F_{l h}, F_{s w}$ and $F_{l w}$ anomaly against the time series of daily averaged $\bar{f}_{w}$ over the sensitive regions in recent 40 winters were calculated separately for all the examined ocean basins. All the regressed fields have similar pattern as their counterparts in Figures 3 6, implying a similar relationship for all WaMAIs but at smaller magnitudes. Since the regressions confirm the conclusions, we will consider only the Barents and Beaufort Seas as an example of ocean sector with open ocean and land-locked sea ice, respectively (Figure 7 and 8).

\subsection{The Surface Energy-budget}

In this section, we will explore the transformation of temperature inversion, cloud formation and surface energybudget along the trajectories of warm-and-moist air masses over ocean basins with open water and land-locked sea ice, respectively, by composite the heights to the maximum specific humidity $\left(h_{s h}\right)$, temperature $\left(h_{t}\right)$ and vertical temperature gradient $\left(h_{t_{z}}\right)$, along with TWP, LWP, IWP, precipitation rate (PRCR) and surface energybudget terms $\left(F_{s h}, F_{l h}, F_{\text {total }}, F_{l w}\right)$ from all detected WaMAIs.

Over the completely ice-covered sea sectors such as the Laptev, East Siberia, Chukchi and Beaufort Seas, strong temperature inversion develops with cloud formation below, as the warm-and-moist air propagates over the sea ice. A detailed analysis of this boundary-layer structure follows in Section 3.3. In this case, $h_{s h}$ is above $h_{t}$, and both higher than $h_{t_{z}}$ (Figure 9a). From the ice edge and onward up to 10 degrees north of the ice edge, $h_{s h}, h_{t}$ and $h_{t_{z}}$ increase almost linearly, by 30-40 $\mathrm{m}$ degree $^{-1}$ (Figure 9a). TCW and PRCP also increase northward, although more slowly for the first two degrees, in total by $6 \mathrm{~g} \mathrm{~m}^{-2}$ degree $^{-1}$ and $0.4 \mathrm{~mm} \mathrm{day}^{-1}$ degree $^{-1}$, respectively, implying that stratocumulus develop continuously along the trajectories (Figure 9b, c). The increasing TWP is mainly due to the increase in IWP since LWP is almost constant along the trajectories (Figure 9b). The increase of $h_{t_{z}}$ is comparable to that of summer WaMAIs, while the increase in TWP is about half of that of summer WaMAIs (You et al., 2021), since less moisture is available for cloud development in winter (Figure 4c).

The gradual increase of $h_{t_{z}}$, a manifestation of increased boundary-layer mixing, leads to a reduction in near-surface gradients. Since the turbulent heat fluxes at the surface are dependent on these gradients, $F_{s h}$ anomaly decreases gradually at a rate of $1.5 \mathrm{~W} \mathrm{~m}^{-2}$ degree $^{-1}$ (Figure 10a). Simultaneously, $F_{l w}$ anomaly increases almost linearly by $2.5 \mathrm{~W} \mathrm{~m}^{-2}$ degree $^{-1}$, while $F_{l h}$, the smallest contributor to $F_{\text {total }}$, are almost constant along the trajectories 
(Figure 10a). The increase in $F_{l w}$ along trajectories is due to the increase in the cloud radiative effects of the stratocumulus. As shown in figure $10 \mathrm{~b}, F_{l w_{-} C R E}$ increases at a similar rate as $F_{l w}$. From 0 to 2 degrees north of the sea ice edge, $F_{\text {total }}$ anomaly is dominated by $F_{s h}$ anomaly, while farther north it is dominated by $F_{l w}$ anomaly (Figure 10a). Generally, $F_{\text {total }}$ anomaly increases with the distance from the sea ice edge at a rate of $1 \mathrm{~W} \mathrm{~m}^{-2}$ degree $^{-1}$ and this increasing trend is dominated by $F_{l w}$ anomaly (Figure 10a).

Over the Barents Sea, with open warm water south of the ice edge, $h_{t}$ and $h_{s h}$ also increase nearly linearly but at a rate 1.6 times larger rate than for ocean sectors with land-locked sea ice, however, at considerably smaller values (Figure 9d). The minimum values of $h_{t}$ and $h_{s p}$ over these completely ice-covered sectors are comparable to the maximum values over the Barents Sea, implying that WaMAIs over the Barents Sea bring the moist and warm air closer to the surface with a shallower PBL. However, the temperature inversion over the Barents Sea is too weak to be easily identified with the metrics used above. Unlike for the sectors with land-locked sea ice, TWP and PRCR are constant with downwind distance from the ice edge, varying slightly around $150 \mathrm{~g} \mathrm{~m}^{-2}$ and $7 \mathrm{~mm}$ day $^{-1}$ (Figure 9e, f). As a consequence, $F_{l w}$ anomaly and $F_{l w_{-} C R E}$ along the trajectories (Figure 10c, d) are nearly constant with northward distance. Although TWP remains quasi-constant, LWP (IWP) decreases (increases) at a rate of $-6 \mathrm{~g} \mathrm{~m}^{-2}\left(+6 \mathrm{~g} \mathrm{~m}^{-2}\right)$ along the trajectories (Figure 9e). From 0 to 4 degrees north of the sea ice edge, TWP is contributed by LWP and IWP in about equal parts, while from 4 degrees north of the sea ice edge and onward, TWP gradually becomes dominated by IWP.

$F_{s h}$ anomaly decreases fast by nearly $50 \%$ over the first two degrees from the sea ice edge (Figure 10c). From 2 to 10 degrees north of the sea ice edge, the decrease is more moderate at a rate of $4 \mathrm{~W} \mathrm{~m}^{-2}$ degree $^{-1}$ (Figure $10 \mathrm{c})$ but still faster than that over the completely frozen ocean sectors. However, $F_{s h}$ anomaly even at ten degrees north of the ice edge is still larger than the largest value of $F_{s h}$ anomaly over the completely frozen ocean sectors (Figure 10a). This is likely due to the much warmer upstream conditions over the open ocean. The large thermal contrast between open ocean and sea ice surface contributes to the stable atmospheric layer over the sea ice surface and rapidly reducing $F_{s h}$ anomaly, while the decrease of $F_{s h}$ anomaly with downstream distance is due to the slowly reducing temperature gradient resulted from the turbulent mixing. Similar decreasing trends are also present for $F_{\text {lh }}$ and $F_{\text {total }}$ anomaly (Figure 10c). From 2 to 10 degrees north of the sea ice edge, they decrease at a rate of 1 and $5 \mathrm{~W} \mathrm{~m}^{-2}$ degree $^{-1}$, respectively (Figure 10c). Within 5 degrees north of the sea ice edge, $F_{\text {total }}$ anomaly is dominated by $F_{s h}$, while downstream the turbulent heat flux $\left(F_{s h}+F_{l h}\right)$ anomaly becomes comparable to $F_{l w}$ anomaly and contribute almost equally to $F_{\text {total }}$ anomaly (Figure 10c).

Without the presence of solar radiation in winter, the variation of $F_{\text {total }}$ anomaly over the Barents Sea is dominated by $F_{s h}$ anomaly (Figure 10a), while it is dominated by $F_{l w}$ anomaly over ocean sectors with land-locked sea ice (Figure 10c). This distinction between ocean sectors with and without open ocean upstream can be explained by the stronger air-sea interaction over the Barents Sea (Kim et al., 2019). Before the air-mass is advected in over the sea ice, it is heated and moistened by the warmer and moister ocean surface and consequently, exerts greater turbulent heat fluxes to the surface as it suddenly enters over the sea ice (Figure 10c). Also, the cloud formation happens already upstream over the warm water and is not much affected by the advection over sea ice. This dominance of turbulent heat fluxes remains until the halfway along the trajectories.

\subsection{The Boundary-layer Energy-budget}


As discussed in previous sections, cloud formation as part of the air-mass transmission can exert large variability on the surface energy-budget. Here, we focus on the cloud effects on the boundary-layer energy-budget. For each WaMAI, the boundary-layer energy-budget terms are evaluated and interpolated along the trajectory and analyzed on a case-by-case basis, categorizing patterns into four main categories: a) lifting temperature inversion (INV); b) radiation-dominated (RAD); c) turbulence-dominated (TBL); and d) turbulence-dominated with cold dome (TCD). Some typical cases are shown in figure 11-14, illustrating different boundary-layer energy-budgets in each category. Almost all WaMAIs over ocean sectors with land-locked sea ice feature a boundary-layer energy-budget pattern of category INV. Similar to category TBL for summer WaMAIs (You et al., 2021), category INV is characterized by increasingly lifting temperature inversion and continuously stratocumulus development near the inversion. Different from the ocean sectors with land-locked sea ice, clouds during WaMAIs over the ocean sector with upstream open ocean (e.g. Barents Sea) form at the altitude of $\sim 1 \mathrm{~km}$, above the warm-and-moist air-masses. The boundary-layer energy-budget here is categorized into three categories (RAD, TBL, TCD). Category RAD is characterized by stronger cloud-top radiative cooling and related buoyant mixing, while category TBL is characterized by more intensive surface turbulent mixing. Category TCD is similar to category TBL excluding a cold dome over the high Arctic. Note that unlike radiation and condensation/evaporation, turbulence does not generate heating/cooling by itself. Instead, it heats/cools air locally by redistributing heat from one altitude to another through mixing within the column. Also, note that the temperature tendencies discussed below are only those that are due to model physics in a Lagrangian view, while in an Eulerian framework, they would be balanced by advection (not shown). In an absolute sense the boundary layer always undergoes a gradual cooling during the advection over the sea ice. Conceptual graphs of all the different categories are summarized in Figure 15.

\subsubsection{Lifting temperature inversion (INV)}

In this category turbulent heating and cooling dominate the boundary-layer energy-budget (Figure 11e and 11h), even though stratocumulus develops along the trajectories and affects the radiative processes (Figure 11a and f). Turbulent mixing transports heat from the upper to the lower parts of the PBL, hence cooling the upper and warming the lower parts of the PBL (Figure 11h). Since the turbulent mixing persists along the trajectories, the well-mixed layer below the inversion continuously deepens northward (Figure 11b), while the inversion and the cloud top are gradually lifted (Figure 11a). This supports the hypothesis from Tjernström et al. (2019b), that the surface inversion formed at the sea ice edge is eroded progressively downstream, by cloud-top cooling and surface turbulent mixing, and eventually the boundary layer must transform into the often observed well-mixed cloudcapped boundary layer (e.g. Tjernström and Graversen 2009; Tjernström et al. 2012; Sotiropoulou et al. 2014; Brooks et al. 2017). Even though this hypothesis was originally posed for summer WaMAIs, it is also applicable for winter WaMAIs over completely frozen ocean sectors; see Figure 15a.

Clouds are relatively thin and radiative cooling near the cloud top is therefore weak (Figure 11f) and only in a few cases the magnitude of radiative cooling is comparable to the turbulent cooling. Generally, in this category, turbulent heating is larger than radiative heating as well as latent heating, and hence boundary-layer warming is dominated by turbulence, but since turbulence only redistribute heat inside the PBL, as a whole it is gradually cooled as the warm air progresses northward.

\subsubsection{Radiation-dominated (RAD)}


Over the Barents Sea, the maximum air temperature (Figure 12a, 13a, 14a) and specific humidity (Figure 12d, $13 \mathrm{~d}, 14 \mathrm{~d}$ ) over open ocean south of the ice edge are always located right above the sea surface as a result of the strong air-sea interaction and are also typically larger than those over ocean sectors with land-locked sea ice. As this air-mass, considerably affected by air-sea interaction, is advected over the sea ice, different stories take place.

Around $8 \%$ of all WaMAIs over the Barents Sea belong to category RAD (Table 2). In this category, the total temperature tendencies are forced by radiative processes. For this category, the large-scale subsidence is an order of magnitude smaller than that in category TBL (Table 3, CONV) and LWP is three times larger than that in category TCD (Table 3, LWP), suggesting that the stratocumulus develops more intensively in category RAD (Figure 12a). With larger values of LWP, longwave radiation is effectively emitted at the cloud top like a black body, exerting large cooling rates with maximum reaching $-16 \mathrm{~K} \mathrm{day}^{-1}$. However, unlike the cloud formation in category INV, here clouds always already form south of the ice edge over the open water and few clouds develop in the near-surface inversion. In the cloud, heat is redistributed with warming at the cloud top and cooling in the lower PBL by buoyant mixing driven by cloud-top longwave radiative cooling (Figure12h). The turbulent cooling layer in the PBL interior is apparently thicker than the turbulent warming layer whose absolute value of heating rate is considerably more intensive (Figure $12 \mathrm{~h}$ ). As shown in figure $12 \mathrm{~h}$, the buoyant mixing can access the surface and induce a thicker well-mixed layer below the stratocumulus (Figure 12b). As precipitation constantly erodes the cloud, buoyant mixing continuously provides moisture for the cloud development from the moister air below and hence cloud development as well as the cloud top cooling is maintained.

Meanwhile, the value of maximum temperature and specific humidity is decreasing gradually along the trajectory, indicating that the heat and moisture within the warm-and-moist air is consumed continuously by the cloud formation and surface turbulent mixing. For this category, $F_{l w}$ is comparable to those of category TBL and TCD (Table 3), and increases almost linearly along the trajectory (Figure 16d1) due to the enhancing TWP (Figure $16 \mathrm{c} 1) . F_{s h}$ and $F_{l h}$ are generally smaller than those of category TBL since stronger mixing weakens vertical gradients in the PBL and hence suppresses the surface turbulent heat flux (Table 3). The decreasing rates of $F_{s h}$ and $F_{l h}$ from 0 to 2 degrees north of the sea ice edge are larger than for categories TBL and TCD as a result of stronger buoyant mixing in the PBL (Figure 16a1), while onwards, their decreasing rates are smaller than those for the other two categories since the lifting rates of $h_{t}$ and $h_{s p}$ are dramatically slowed down (Figure 16b1); see Figure $15 b$.

\subsubsection{Turbulence-dominated (TBL)}

$52 \%$ of WaMAIs over the Barents Sea belong to the turbulence dominated category. The variation of surface energy-budget along the trajectory (Figure 16 a2, b2 and c2) is similar to the mean variation of WaMAIs from all categories showed in figure $10 \mathrm{c}$ and $10 \mathrm{~d}$. Subsidence for WaMAIs in this category is typically a factor of three larger than that in category RAD and it is statistically significantly positive (Table 3, CONV). Consequently, clouds in this category do not develop as intensively as in category RAD and hence the radiative cooling rate at the cloud top is considerably smaller. The boundary-layer energy-budget is mainly dominated by turbulent heating near the surface. As warm-and-moist air is advected into the Arctic sea ice, turbulence exchanges heat between warm and cold air-mass by cooling (heating) warmer (colder) air (Figure 13h), simultaneously inducing a gradually thickening well-mixed layer capped by a strong inversion, and a continuously lifting of $h_{t}$ and $h_{s p}$ (Figure 
13b). In this category, the well-mixed layer is substantially thinner than in category RAD, since the turbulent mixing here is mainly forced by surface friction, weaker and less effective than the buoyant mixing in category RAD (Figure 12b). Turbulence is mainly forced by wind shear and buoyancy, but buoyancy is negative here in the initially very stable near-surface layer. Therefore, wind shear mostly fuels the turbulent mixing. In category TBL, turbulent mixing is stronger than in category RAD, but the surface fluxes are still stronger, due to the stronger gradients; $F_{s h}$ and $F_{l h}$ are $77 \%$ and $42 \%$ larger than those in category RAD. Also see Figure 15c.

\subsubsection{Turbulence-dominated with cold dome (TCD)}

$40 \%$ of WaMAIs over the Barents Sea belong to this category. For this category, the boundary-layer energybudget is generally similar to that in category TBL. The main difference is that there is always a layer of cold air (cold dome) laying below the warm-and-moist air-mass especially in the central Arctic (Figure 14c). This cold dome enlarges the vertical temperature gradient and hence intensifies turbulent heat near the surface (Figure 14h). As the warm-and-moist air-mass is advected over the cold dome, it is gradually lifted up by the cold dome and consequently, $h_{t}$ and $h_{s p}$ are increasing at a faster rate than in category TBL (Figure 16b3). With faster lifting $h_{t}$ and $h_{s p}, F_{s h}$ and $F_{l h}$ would be reduced more rapidly or even become negative in the high Arctic (Figure 16a3). Unlike in category RAD, where TWP is dominated by LWP, and category TBL, where TWP is contributed almost equally by LWP and IWP, in this category TWP is gradually more dominated by IWP; the IWP-to-TWP ratio increases linearly from $\sim 50 \%$ to $\sim 100 \%$ (Figure 16c3); also see Figure 15d.

\section{Conclusion}

Warm-and-moist air intrusions (WaMAI) greatly contribute to Arctic surface warming. To understand the surface and boundary-layer energy-budget as WaMAIs occur, in this paper, we have detected WaMAIs over the Arctic Ocean sectors of Barents, Kara, Laptev, East Siberian, Chukchi and Beaufort Seas in 40 recent winters (DJF from 1979 to 2018) using ERA5 reanalysis. The climatological analysis shows a consistent pattern with a blocking high-pressure system over corresponding ocean sectors contribute to warm-and-moist air intrusions into winter Arctic, supplying moisture for cloud formation, exerting a positive total energy-budget anomaly on the surface.

Statistically, as warm-and-moist air is advected over ocean sectors with land-locked ice cover, such as the Laptev, East Siberian, Chukchi and Beaufort Seas, the longwave irradiance anomaly increases linearly by 2.5 $\mathrm{W} \mathrm{m} \mathrm{m}^{-2}$ degree $^{-1}$, while the total column cloud liquid water increases linearly by $6 \mathrm{~g} \mathrm{~m}^{-2}$ degree $^{-1}$. We have also analysed the boundary-layer vertical structure along these trajectories, as well as the associated surface energybudget pattern of over these sectors, and find one main category, elevated lifting temperature inversion (INV), which in structure is similar to summer WaMAIs (You et al., 2021) (Figure 15a).

WaMAIs over the Barents Sea, with open ocean south of the ice edge, are found in three main categories: radiation-dominated (category RAD), turbulence-dominated (category TBL) and turbulent-dominated with cold dome (category TCD), comprising $8 \%, 52 \%$ and $40 \%$, respectively, of all WaMAIs. Unlike over the sectors with land-locked sea ice, air-masses over the ice-free Barents Sea is warmed by the sea surface (local process) before advected over the sea ice (remote process), consequently resulting in more intensive surface warming.

In response to ten times smaller large-scale subsidence, stratocumulus develops more strongly in category RAD with more intensive cloud-top radiative cooling, inducing apparently thicker well-mixed layer 
(Figure 15b). However, this strong radiative cooling induces intensive buoyant mixing extending from the cloud top till the surface, supresses the surface turbulent mixing and decreases the lifting rate of the height to the maximum temperature $\left(h_{t}\right)$ and to the maximum specific humidity $\left(h_{s p}\right)$. Therefore, surface turbulent fluxes in category RAD and the lifting rate of $h_{t}$ and $h_{s p}$ are apparently smaller than those in category TBL (Figure 15c). With cold dome, less liquid cloud water could be formed and fewer or even negative turbulent fluxes could access to the surface, in comparison with category TBL (Figure 15d). In category TCD, turbulent fluxes decrease faster along the trajectory since warm-and-moist air is lifted to higher altitude above the cold dome (Figure 15d).

Under the background of global warming, the rate of local process has been accelerated by $9 \%$ per year (Kim et al., 2019), while the meridional heat and moisture transports (remote processes) over the Barents Sea are also enhanced in recent decades (Nygård et al., 2020). This implies that WaMAI may play a more significant role in the future Arctic warming. Therefore, the potential mechanism which enhances the occurrence and intensity of WaMAI deserves more attentions from atmospheric scientists.

\section{Data availability}

All data used can be found on the ERA5 data repository at DOI: $\underline{w w w . e c m w f . i n t / e n / f o r e c a s t s / d a t a s e t s / r e a n a l y s i s-~}$ datasets/era5.

\section{Author contributions}

CY conducted analysis and interpretation of the data under the supervision of MT and AD. CY prepared the original version of the paper. $\mathrm{MT}$ and $\mathrm{AD}$ provided constructive comments and revisions to the final article.

\section{Competing interests}

The authors declare that they have no conflict of interest.

\section{Acknowledgements:}

This research was supported by the Swedish Research Council under Grant 2016-03807. The authors are grateful to Cian Woods for providing the trajectory calculation algorithm.

\section{References}

Cohen, J., Screen, J. A., Furtado, J. C., Barlow, M., Whittleston, D., Coumou, D., Francis, J., Dethloff, K., Entekhabi, D., Overland, J. and Jones, J.: Recent Arctic amplification and extreme mid-latitude weather, Nat. Geosci., 7(9), 627-637, doi:10.1038/ngeo2234, 2014.

Cox, C. J., Stone, R. S., Douglas, D. C., Stanitski, D. M. and Gallagher, M. R.: The Aleutian Low-Beaufort Sea Anticyclone: A Climate Index Correlated With the Timing of Springtime Melt in the Pacific Arctic Cryosphere, Geophys. Res. Lett., 46(13), 7464-7473, doi:10.1029/2019GL083306, 2019.

Francis, J. A. and Vavrus, S. J.: Evidence linking Arctic amplification to extreme weather in mid-latitudes, Geophys. Res. Lett., 39(6), doi:10.1029/2012GL051000, 2012. 

trend, J. Clim., 30(13), 4937-4949, doi:10.1175/JCLI-D-16-0180.1, 2017. warming, Nature, 451(7174), 53-56, doi:10.1038/nature06502, 2008. Radu, R., Schepers, D., Simmons, A., Soci, C., Abdalla, S., Abellan, X., Balsamo, G., Bechtold, P., Biavati, G., Bidlot, J., Bonavita, M., De Chiara, G., Dahlgren, P., Dee, D., Diamantakis, M., Dragani, R., Flemming, J., Forbes, R., Fuentes, M., Geer, A., Haimberger, L., Healy, S., Hogan, R. J., Hólm, E., Janisková, M., Keeley, S., Laloyaux, P., Lopez, P., Lupu, C., Radnoti, G., de Rosnay, P., Rozum, I., Vamborg, F., Villaume, S. and Thépaut, J. N.: The ERA5 global reanalysis, Q. J. R. Meteorol. Soc., 146(730), 1999-2049, doi:10.1002/qj.3803, 2020

381

Kim, B. M., Son, S. W., Min, S. K., Jeong, J. H., Kim, S. J., Zhang, X., Shim, T. and Yoon, J. H.: Weakening of the stratospheric polar vortex by Arctic sea-ice loss, Nat. Commun., doi:10.1038/ncomms5646, 2014.

Kim, K. Y. and Son, S. W.: Physical characteristics of Eurasian winter temperature variability, Environ. Res. Lett., doi:10.1088/1748-9326/11/4/044009, 2016.

Kim, K. Y., Kim, J. Y., Kim, J., Yeo, S., Na, H., Hamlington, B. D. and Leben, R. R.: Vertical Feedback Mechanism of Winter Arctic Amplification and Sea Ice Loss, Sci. Rep., doi:10.1038/s41598-018-38109-x, 2019.

Komatsu, K. K., Alexeev, V. A., Repina, I. A. and Tachibana, Y.: Poleward upgliding Siberian atmospheric rivers over sea ice heat up Arctic upper air, Sci. Rep., 8(1), doi:10.1038/s41598-018-21159-6, 2018.

Liu, Y., Key, J. R., Vavrus, S. and Woods, C.: Time evolution of the cloud response to moisture intrusions into the Arctic during Winter, J. Clim., 31(22), 9389-9405, doi:10.1175/JCLI-D-17-0896.1, 2018.

Messori, G., Woods, C. and Caballero, R.: On the drivers of wintertime temperature extremes in the high arctic, J. Clim., 31(4), 1597-1618, doi:10.1175/JCLI-D-17-0386.1, 2018.

Mori, M., Watanabe, M., Shiogama, H., Inoue, J. and Kimoto, M.: Robust Arctic sea-ice influence on the frequent Eurasian cold winters in past decades, Nat. Geosci., doi:10.1038/ngeo2277, 2014.

Morrison, H., De Boer, G., Feingold, G., Harrington, J., Shupe, M. D. and Sulia, K.: Resilience of persistent Arctic mixed-phase clouds, Nat. Geosci., 5(1), 11-17, doi:10.1038/ngeo1332, 2012.

Nygård, T., Naakka, T. and Vihma, T.: Horizontal moisture transport dominates the regional moistening patterns in the arctic, J. Clim., doi:10.1175/JCLI-D-19-0891.1, 2020.

Overland, J. E. and Wang, M.: Recent extreme arctic temperatures are due to a split polar vortex, J. Clim., 29(15), 5609-5616, doi:10.1175/JCLI-D-16-0320.1, 2016. 
402

Overland, J. E., Wood, K. R. and Wang, M.: Warm Arctic-cold continents: Climate impacts of the newly open arctic sea, Polar Res., doi:10.3402/polar.v30i0.15787, 2011.

Petoukhov, V. and Semenov, V. A.: A link between reduced Barents-Kara sea ice and cold winter extremes over northern continents, J. Geophys. Res. Atmos., doi:10.1029/2009JD013568, 2010.

Pithan, F., Medeiros, B. and Mauritsen, T.: Mixed-phase clouds cause climate model biases in Arctic wintertime temperature inversions, Clim. Dyn., 43(1-2), 289-303, doi:10.1007/s00382-013-1964-9, 2014.

Sedlar, J. and Tjernström, M.: Clouds, warm air, and a climate cooling signal over the summer Arctic, Geophys. Res. Lett., 44(2), 1095-1103, doi:10.1002/2016GL071959, 2017.

Serreze, M. C. and Francis, J. A.: The arctic amplification debate, Clim. Change, 76(3-4), 241-264, doi:10.1007/s10584-005-9017-y, 2006.

Simmonds, I.: Comparing and contrasting the behaviour of Arctic and Antarctic sea ice over the 35 year period 1979-2013, Ann. Glaciol., 56(69), 18-28, doi:10.3189/2015AoG69A909, 2015.

Sotiropoulou, G., Sedlar, J., Tjernström, M., Shupe, M. D., Brooks, I. M. and Persson, P. O. G.: The thermodynamic structure of summer Arctic stratocumulus and the dynamic coupling to the surface, Atmos. Chem. Phys., 14(22), 12573-12592, doi:10.5194/acp-14-12573-2014, 2014.

Tang, Q., Zhang, X., Yang, X. and Francis, J. A.: Cold winter extremes in northern continents linked to Arctic sea ice loss, Environ. Res. Lett., doi:10.1088/1748-9326/8/1/014036, 2013.

Tjernström, M., Shupe, M. D., Brooks, I. M., Persson, P. O. G., Prytherch, J., Salisbury, D. J., Sedlar, J., Achtert, P., Brooks, B. J., Johnston, P. E., Sotiropoulou, G. and Wolfe, D.: Warm-air advection, air mass transformation and fog causes rapid ice melt, Geophys. Res. Lett., 42(13), 5594-5602, doi:10.1002/2015GL064373, 2015.

Tjernström, M., Shupe, M. D., Brooks, I. M., Achtert, P., Prytherch, J. and Sedlar, J.: Arctic summer airmass transformation, surface inversions, and the surface energy budget, J. Clim., 32(3), 769-789, doi:10.1175/JCLID-18-0216.1, 2019.

Woods, C. and Caballero, R.: The role of moist intrusions in winter arctic warming and sea ice decline, J. Clim., 29(12), 4473-4485, doi:10.1175/JCLI-D-15-0773.1, 2016.

Woods, C., Caballero, R. and Svensson, G.: Large-scale circulation associated with moisture intrusions into the Arctic during winter, Geophys. Res. Lett., 40(17), 4717-4721, doi:10.1002/grl.50912, 2013.

You, C., Tjernström, M. and Devasthale, A.: Warm-Air Advection Over Melting Sea-Ice: A Lagrangian Case Study, Boundary-Layer Meteorol., doi:10.1007/s10546-020-00590-1, 2020.

You, C., Tjernström, M. and Devasthale, A.: Eulerian and Lagrangian views of warm and moist air intrusions into summer Arctic, Atmos. Res., 256, doi:10.1016/j.atmosres.2021.105586, 2021. 
Table 1. Regional averaged $F_{s h}, F_{l h}, F_{s w}, F_{l w}$ and $F_{\text {total }}$ in Kara, Laptev, East Siberian and Beaufort Sea sector. The unit is $\mathrm{W} \mathrm{m}^{-2}$ for all variables. Statistically significant positive values are in bold.

\begin{tabular}{|ccccccc|}
\hline $\begin{array}{c}\text { Sea } \\
\text { sector }\end{array}$ & Barents & Kara & Laptev & $\begin{array}{c}\text { East } \\
\text { Siberian }\end{array}$ & Chukchi & Beaufort \\
$\boldsymbol{F}_{\boldsymbol{s h}}$ & $\mathbf{2 8 . 8 5} \pm \mathbf{1 6 . 7 3}$ & $8.92 \pm 13.08$ & $3.17 \pm 6.53$ & $6.72 \pm 7.77$ & $\mathbf{1 3 . 5 5} \pm \mathbf{1 0 . 8 7}$ & $5.93 \pm 8.14$ \\
$\boldsymbol{F}_{\boldsymbol{l h}}$ & $\mathbf{1 0 . 0 5} \pm \mathbf{9 . 8 3}$ & $0.65 \pm 6.58$ & $-0.39 \pm 2.19$ & $0.55 \pm 2.56$ & $1.56 \pm 4.02$ & $0.34 \pm 2.19$ \\
$\boldsymbol{F}_{\boldsymbol{s} \boldsymbol{w}}$ & $-0.024 \pm 0.59$ & $-0.077 \pm 0.40$ & $-0.029 \pm 0.40$ & $-0.16 \pm 0.47$ & $-0.095 \pm 0.97$ & $-0.077 \pm 0.9$ \\
$\boldsymbol{F}_{\boldsymbol{l w}}$ & $\mathbf{1 5 . 9 9} \pm \mathbf{1 4 . 3 4}$ & $\mathbf{1 6 . 5 1} \pm \mathbf{9 . 9 3}$ & $5.92 \pm 10.88$ & $\mathbf{1 5 . 4 2} \pm \mathbf{1 1 . 1 6}$ & $\mathbf{2 1 . 7 7} \pm \mathbf{1 0 . 3 0}$ & $\mathbf{1 7 . 4 5} \pm \mathbf{1 0 . 5 1}$ \\
$\boldsymbol{F}_{\text {total }}$ & $\mathbf{5 4 . 8 6} \pm \mathbf{3 4 . 4 1}$ & $\mathbf{2 6 . 0 1} \pm \mathbf{2 5 . 3 2}$ & $8.67 \pm 13.81$ & $\mathbf{2 2 . 5 2} \pm \mathbf{1 5 . 0 8}$ & $\mathbf{3 6 . 7 8} \pm \mathbf{1 6 . 2 7}$ & $\mathbf{2 3 . 6 5} \pm \mathbf{1 4 . 8 5}$ \\
\hline
\end{tabular}

Table 2. Number of WaMAIs with boundary layer energy budget pattern of category RAD (radiation-dominated), TBL (turbulence-dominated), TCD (turbulence-dominated with cold dome) and INV (lifting temperature inversion), over melting (Barents) and frozen (Laptev, East Siberian, Chukchi and Beaufort) sea sectors.

\begin{tabular}{|c|c|c|c|c|}
\hline Sea sector & \multicolumn{3}{|c|}{ Melting } & Frozen \\
\hline Category & RAD & TBL & TCD & INV \\
\hline Number & 9 & 45 & 33 & 131 \\
\hline
\end{tabular}

Table 3. Averaged $F_{s h}, F_{l h}, F_{s w}, F_{l w}$, TCLW (from bottom to $h_{t_{z}} ; \mathrm{g} \mathrm{m}^{-2}$ ) and large-scale convergence (CONV; $10^{-5} \mathrm{~kg} \mathrm{~m}^{-2} \mathrm{~s}^{-1}$ ) from category TBL and category RAD. Statistically significant positive values are in bold.

\begin{tabular}{|llll|}
\hline & Category RAD & Category TBL & \multicolumn{1}{c|}{ Category TCD } \\
$\boldsymbol{F}_{s w}$ & $-0.0094 \pm 0.047$ & $-0.00035 \pm 0.0013$ & $-0.0050 \pm 0.035$ \\
$\boldsymbol{F}_{l w}$ & $\mathbf{3 1 . 4 9} \pm \mathbf{1 3 . 9 6}$ & $\mathbf{3 4 . 6 1} \pm \mathbf{1 8 . 7 1}$ & $\mathbf{3 5 . 4 6} \pm \mathbf{1 3 . 1 0}$ \\
$\boldsymbol{F}_{s h}$ & $\mathbf{4 0 . 9 9} \pm \mathbf{2 8 . 2 7}$ & $\mathbf{7 2 . 5 8} \pm \mathbf{4 0 . 2 1}$ & $9.77 \pm 23.08$ \\
$\boldsymbol{F}_{l h}$ & $\mathbf{1 7 . 4 3} \pm \mathbf{1 5 . 4 2}$ & $\mathbf{2 4 . 7 9} \pm \mathbf{2 3 . 8 0}$ & $1.02 \pm 8.16$ \\
TCLW & $\mathbf{9 6 . 7 8} \pm \mathbf{5 3 . 3 1}$ & $\mathbf{8 3 . 1 1} \pm \mathbf{5 4 . 2 7}$ & $30.13 \pm 31.89$ \\
CONV & $17.19 \pm 174.89$ & $\mathbf{2 3 6 . 0 5} \pm \mathbf{2 2 5 . 9 0}$ & $115.00 \pm 230.01$ \\
Wind Shear & $\mathbf{0 . 0 1 9} \pm \mathbf{0 . 0 0 6 1}$ & $\mathbf{0 . 0 2 6} \pm \mathbf{0 . 0 0 8}$ & $\mathbf{0 . 0 2} \pm \mathbf{0 . 0 1 1}$ \\
\hline
\end{tabular}




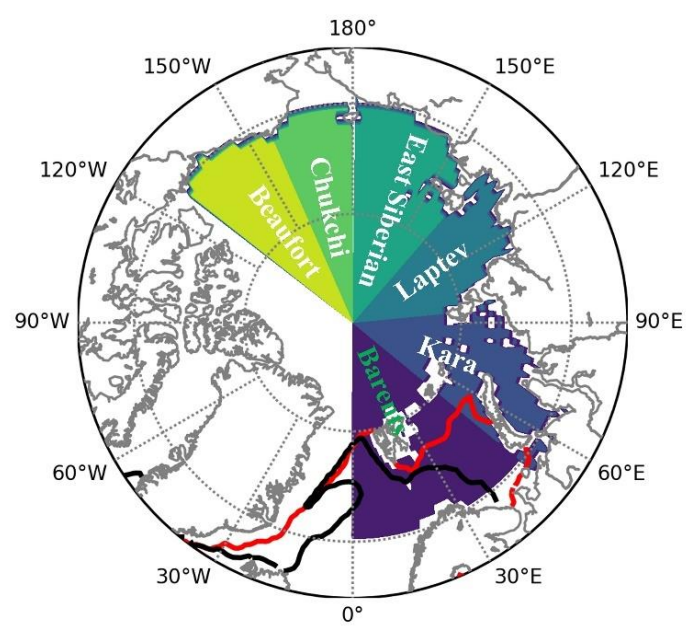

448 Figure 1. Locations of sic sea sectors discussed in this paper, the Barents, Kara, Laptev, East 449 Siberian, Chukchi and Beaufort Sea sectors. Black line is the mean March sea-ice edge in 4501979 and red line is the mean March sea-ice edge in 2015 when the minimum winter sea ice 451 cover was recorded. 


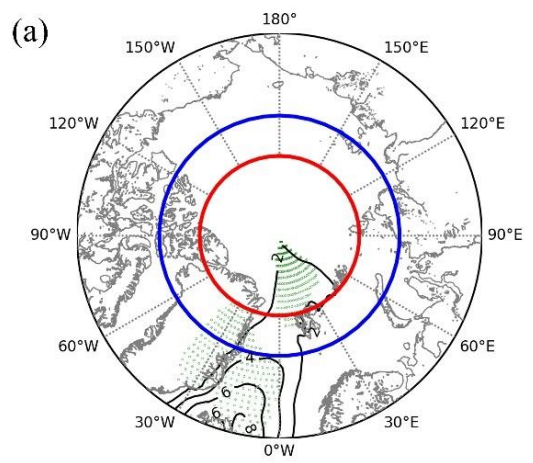

(b) PDF of $\bar{f}_{w}\left(\mathrm{~kg} \mathrm{~m}^{-1} \mathrm{~s}^{-1}\right)$

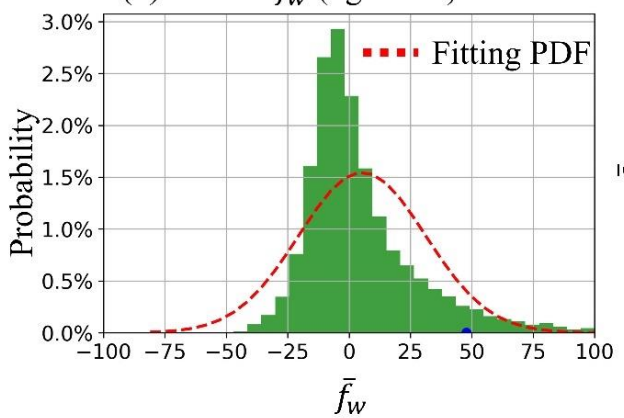

(d) PDF of $\bar{f}_{w}\left(\mathrm{~kg} \mathrm{~m}^{-1} \mathrm{~s}^{-1}\right)$

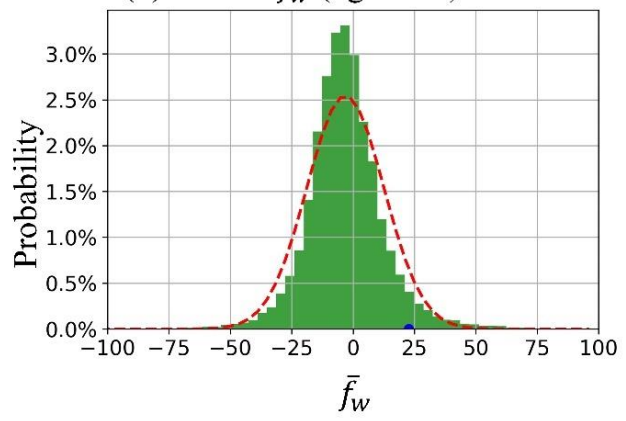

(c) Time Series of $\bar{f}_{w}\left(\mathrm{~kg} \mathrm{~m}^{-1} \mathrm{~s}^{-1}\right)$

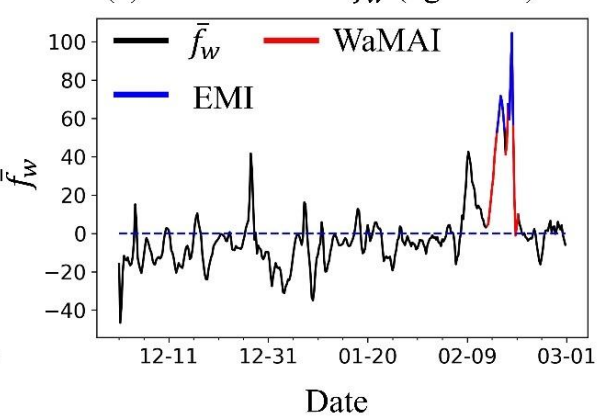

(e) Time Series of $\bar{f}_{w}\left(\mathrm{~kg} \mathrm{~m}^{-1} \mathrm{~s}^{-1}\right)$

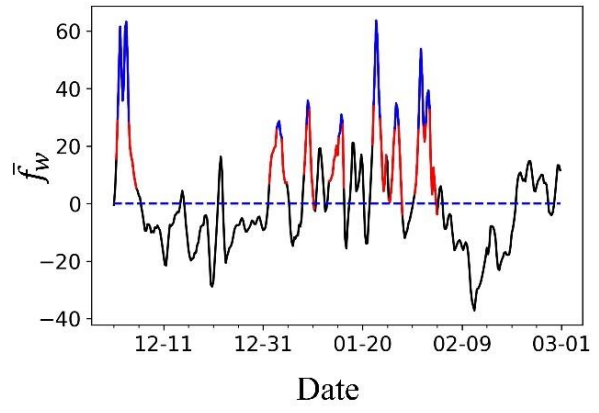

453

454

Figure 2. (a) Contours of the correlation between local $f_{w}$ and SIC anomalies (multiplied by 1) for the winter month (DJF) over the Barents Sea. The stippling indicates statistical significance at the $p<0.05$ level for the Student's $t$ test. Red line is the latitude of $80^{\circ} \mathrm{N}$ where the trajectories over the Barents Sea are launched, while blue line is the latitude of $75^{\circ} \mathrm{N}$ where the trajectories are launched over the sea sectors of Kara, Laptev, East Siberian, Chukchi and Beaufort; (b) and (d) show the Probability Distribution Function of $\bar{f}_{w}$ over the Barents and Beaufort Sea, respectively, with the 95-percentile marked as a blue dot; (c) and (e) are the time 
461 series of $\bar{f}_{w}$ over the Barents Sea and Beaufort Sea in 1980, respectively, with WaMAI 462 highlighted in red and EMIs highlighted in blue.

463

464

465

466

467

468

469

470

471
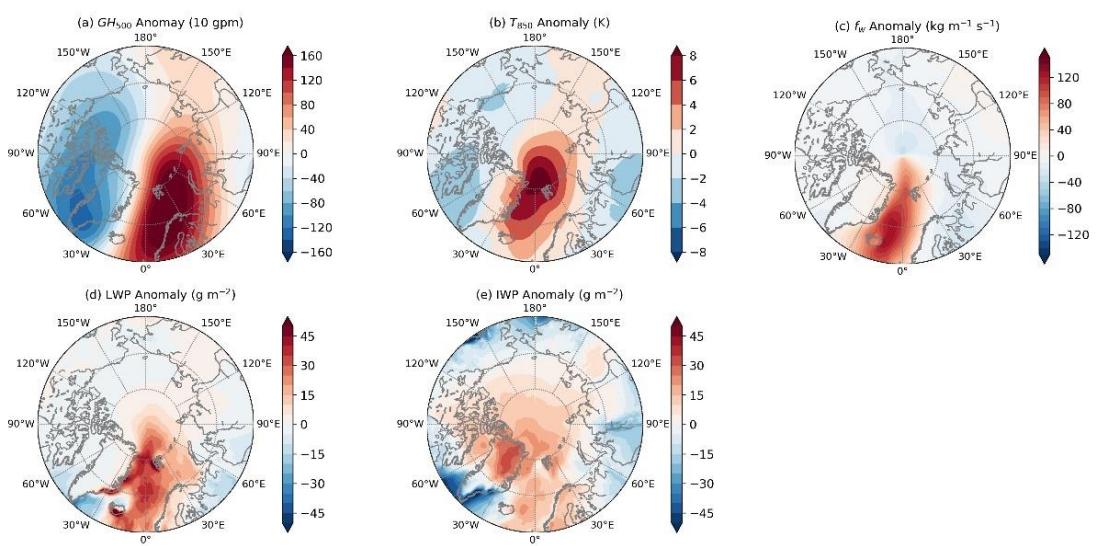

473 Figure 3. Composite ERA5 anomalies of (a) 500-hPa GH (10 gpm), (b) 850-hPa temperature $(\mathrm{K})$, (c) northward water-vapor flux $\left(\mathrm{kgm}^{-1} \mathrm{~s}^{-1}\right)$, (d) liquid water path $\left(\mathrm{g} \mathrm{m}^{-2}\right)$, and (e) ice water path for all EMIs over the Barents Sea, during 1979 2018 winters. 

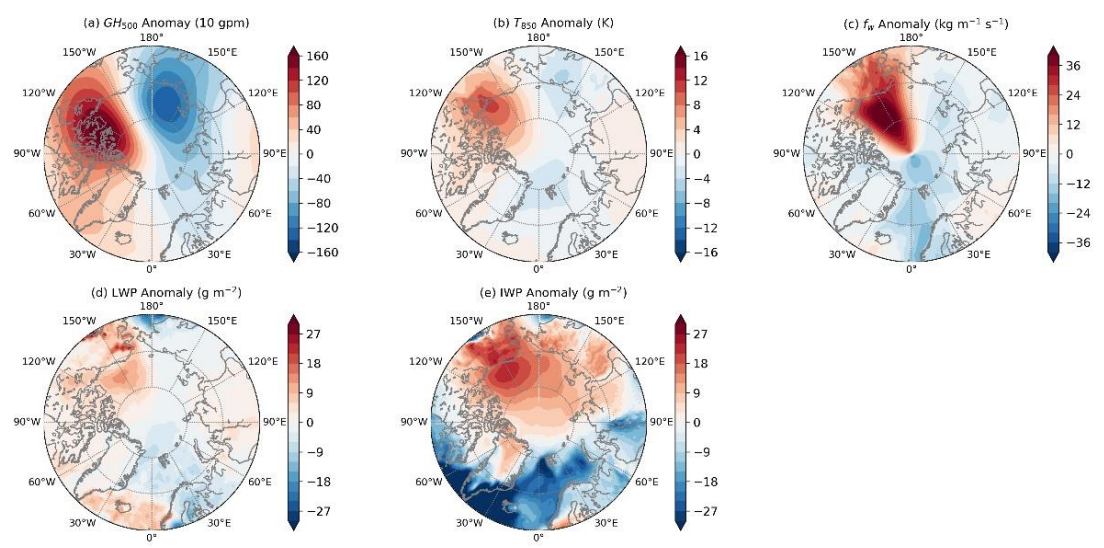

477

478

479

480

481

482

483

484

485

486

487

488
Figure 4. Composite ERA5 anomalies of (a) 500-hPa GH (10 gpm), (b) 850-hPa temperature $(\mathrm{K})$, (c) northward water-vapor flux $\left(\mathrm{kgm}^{-1} \mathrm{~s}^{-1}\right)$, (d) liquid water path $\left(\mathrm{g} \mathrm{m}^{-2}\right)$, and (e) ice water path for all EMIs over the Beaufort Sea, during 1979 2018 winters.
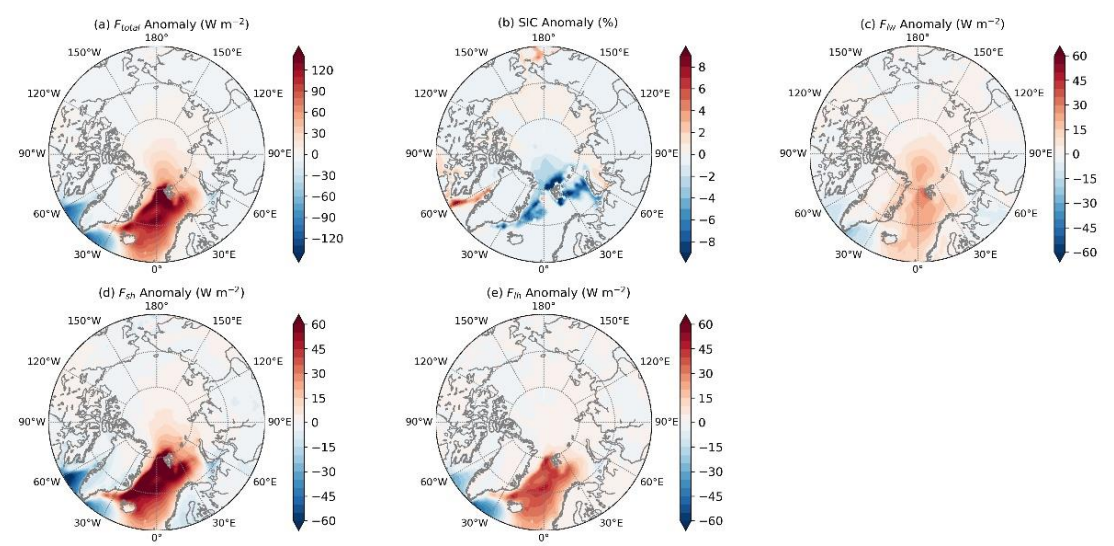

Figure 5. Composite ERA5 anomalies of (a) total surface energy $\left(\mathrm{W} \mathrm{m}^{-2}\right)$, (b) sea ice concentration (\%), (c) surface thermal net irradiance $\left(\mathrm{W} \mathrm{m}^{-2}\right)$, (d) surface sensible heat flux $\left(\mathrm{W} \mathrm{m}^{-2}\right)$ and (e) surface latent heat flux $\left(\mathrm{W} \mathrm{m}^{-2}\right)$ for all EMIs over the Barents Sea, during 1979 2018 winter. 

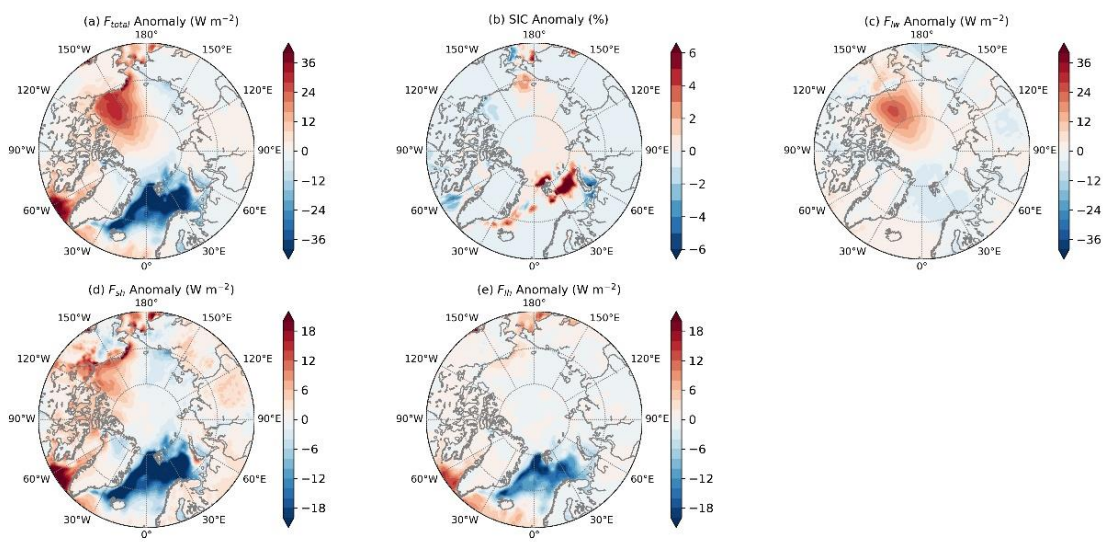

489

490 Figure 6. Composite ERA5 anomalies of (a) total surface energy ( $\mathrm{W} \mathrm{m}^{-2}$ ), (b) sea ice

491 concentration (\%), (c) surface thermal net irradiance $\left(\mathrm{W} \mathrm{m}^{-2}\right)$, (d) surface sensible heat flux

$492\left(\mathrm{~W} \mathrm{~m}^{-2}\right)$ and (e) surface latent heat flux $\left(\mathrm{W} \mathrm{m}^{-2}\right)$ for all EMIs over the Beaufort Sea, during 493 1979 2018 winter. 
https://doi.org/10.5194/acp-2021-610

Preprint. Discussion started: 17 August 2021

(c) Author(s) 2021. CC BY 4.0 License.
Atmospheric

Chemistry and Physics

Discussions

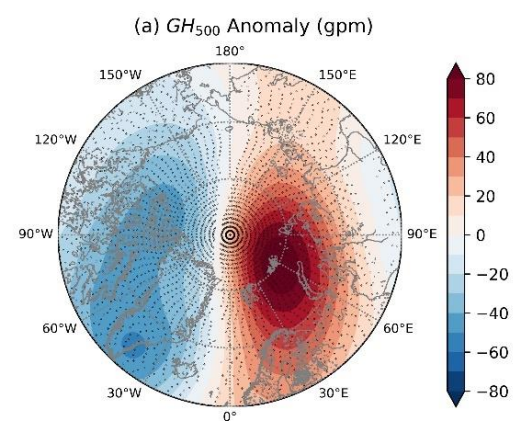

(c) $F_{\text {total }}$ Anomaly $\left(\mathrm{W} \mathrm{m}^{-2}\right)$

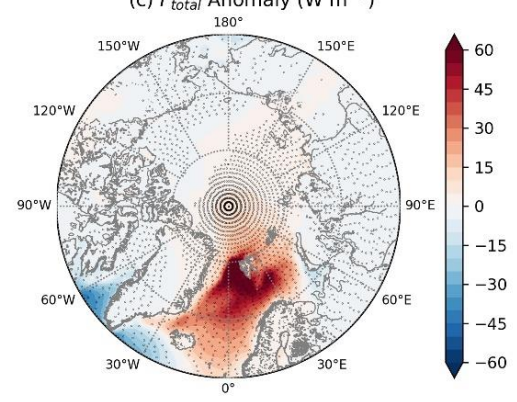

(e) $F_{l w}$ Anomaly $\left(W^{-2}\right.$ )

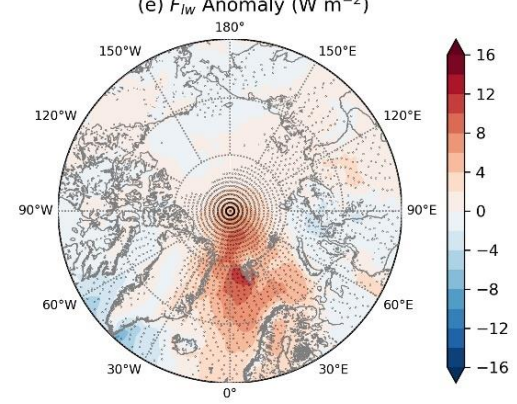

(g) $F_{l h}$ Anomaly $\left(\mathrm{W} \mathrm{m}^{-2}\right)$

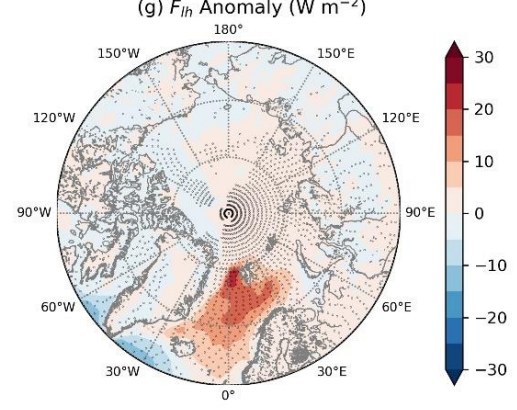

(b) $T_{850}$ Anomaly (K)

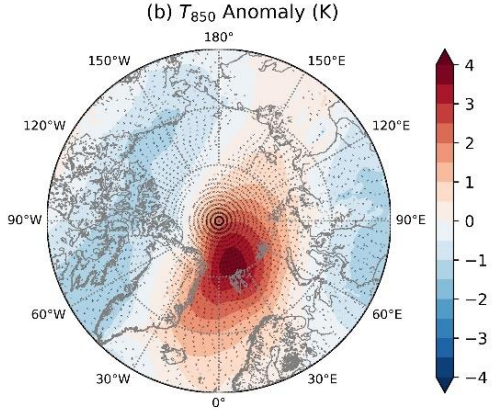

(d) SIC Anomaly (\%)

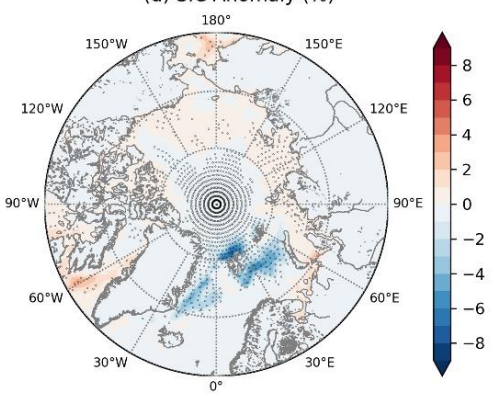

(f) $F_{s h}$ Anomaly $\left(\mathrm{W} \mathrm{m}^{-2}\right)$

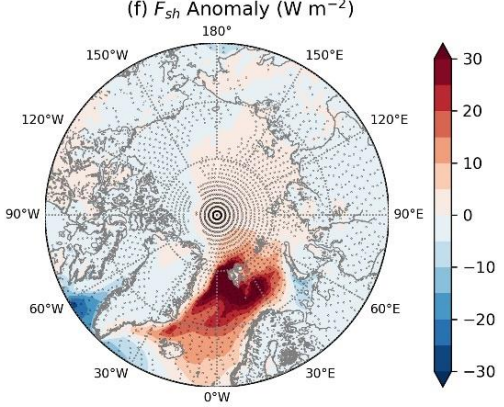

Figure 7. Anomalies of (a) 500-hPa geopotential height (gpm), (b) 850-hPa temperature (K), 
https://doi.org/10.5194/acp-2021-610

Preprint. Discussion started: 17 August 2021

(c) Author(s) 2021. CC BY 4.0 License.

498 series over the Barents Sea. The stippling indicates statistical significance at the $p<0.05$ level from a Student's $t$ test.

500

501 


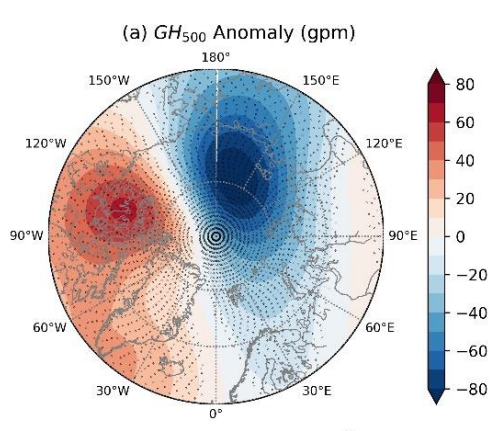

(c) $F_{\text {total }}$ Anomaly $\left(\mathrm{W} \mathrm{m}^{-2}\right)$

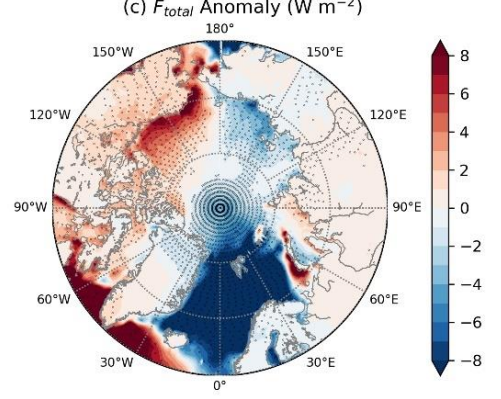

(e) $F_{/ W}$ Anomaly $\left(\mathrm{W} \mathrm{m}^{-2}\right)$

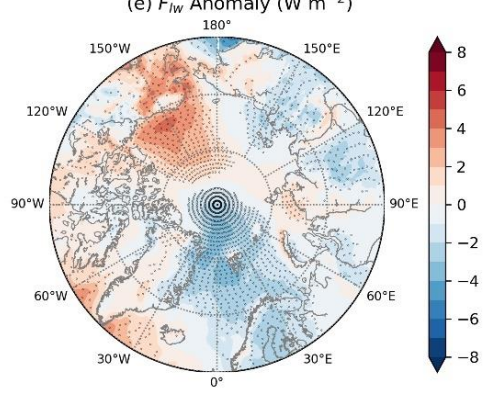

(g) $F_{\text {ih }}$ Anomaly $\left(\mathrm{W} \mathrm{m}^{-2}\right)$

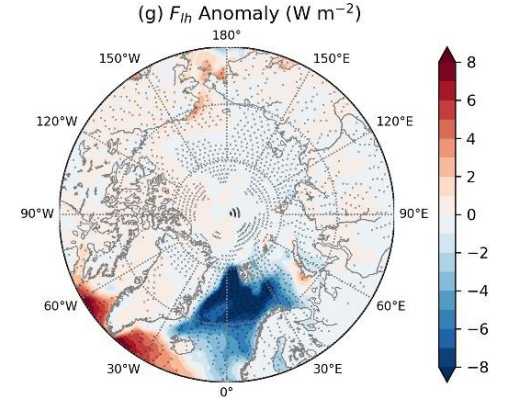

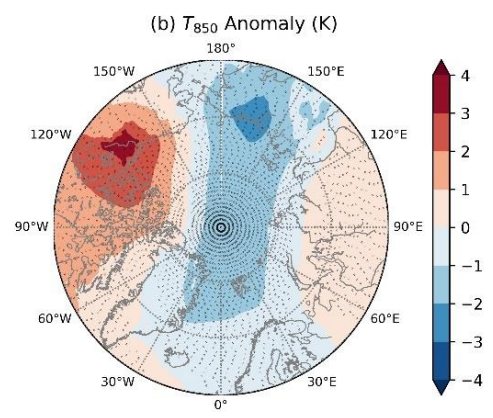

(d) SIC Anomaly (\%)

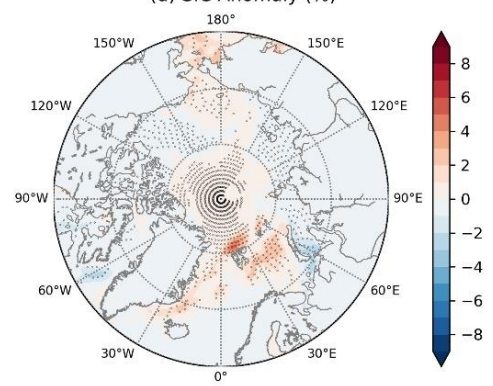

(f) $F_{s h}$ Anomaly $\left(\mathrm{W} \mathrm{m}^{-2}\right)$

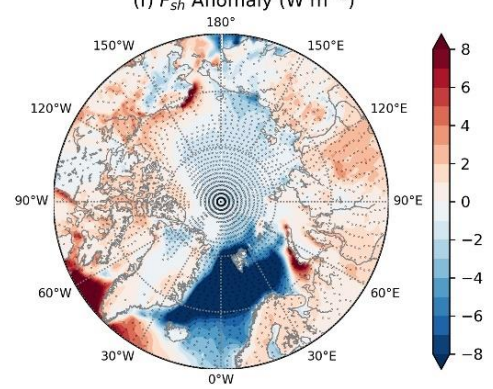

Figure 8. Anomalies of (a) 500-hPa geopotential height (gpm), (b) 850-hPa temperature (K), (c) $F_{\text {total }}$, (d) SIC, (e) $F_{l w}$, (f) $F_{s h}$, and (g) $F_{l h}$ from linear regressions against daily $\bar{f}_{w}$ time series over the Beaufort Sea. The stippling indicates statistical significance at the $p<0.05$ level from a Student's $t$ test. 

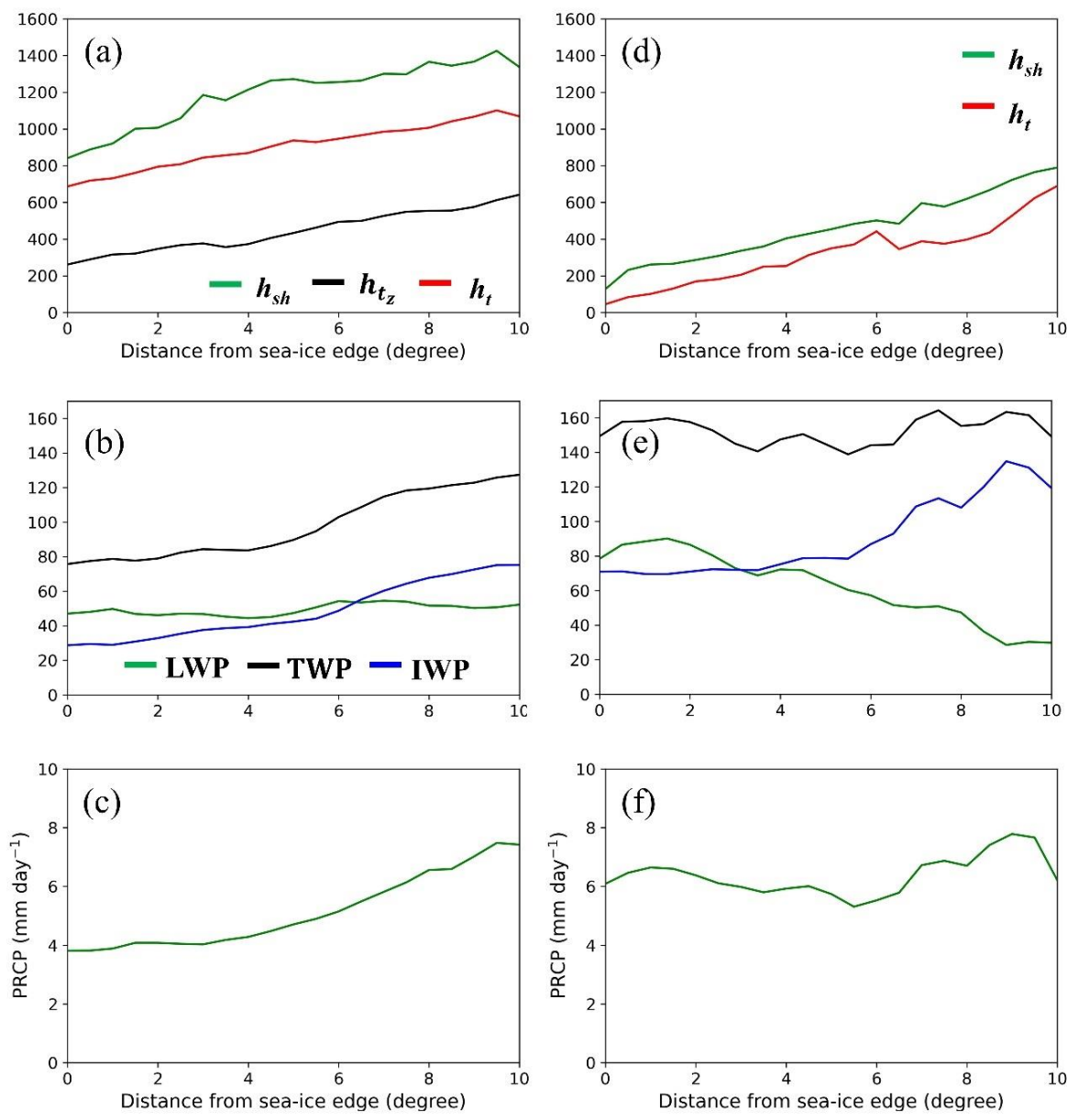

Figure 9: Average variation of (a) the height to the maximum specific humidity $\left(h_{s h}\right)$, temperature gradient $\left(h_{t_{z}} ; \mathrm{m}\right)$ and temperature $\left(h_{t}\right)$; (b) liquid water path (LWP; $\left.\mathrm{g} \mathrm{m}^{-2}\right)$, ice water path (IWP; $\mathrm{g} \mathrm{m}^{-2}$ ) and total water path (TWP; $\mathrm{g} \mathrm{m}^{-2}$ ); (c) precipitation rate (PRCP; $\mathrm{mm}$ day $^{-1}$ ), with the downstream northward distance from sea-ice edge, along the WaMAI trajectories over the Barents Sea. (d) (e) (f) are the counterparts of (a)(b)(c) over the frozen seas. Note that this is not necessarily the distance travelled, since WaMAIs need to travel due northward. 

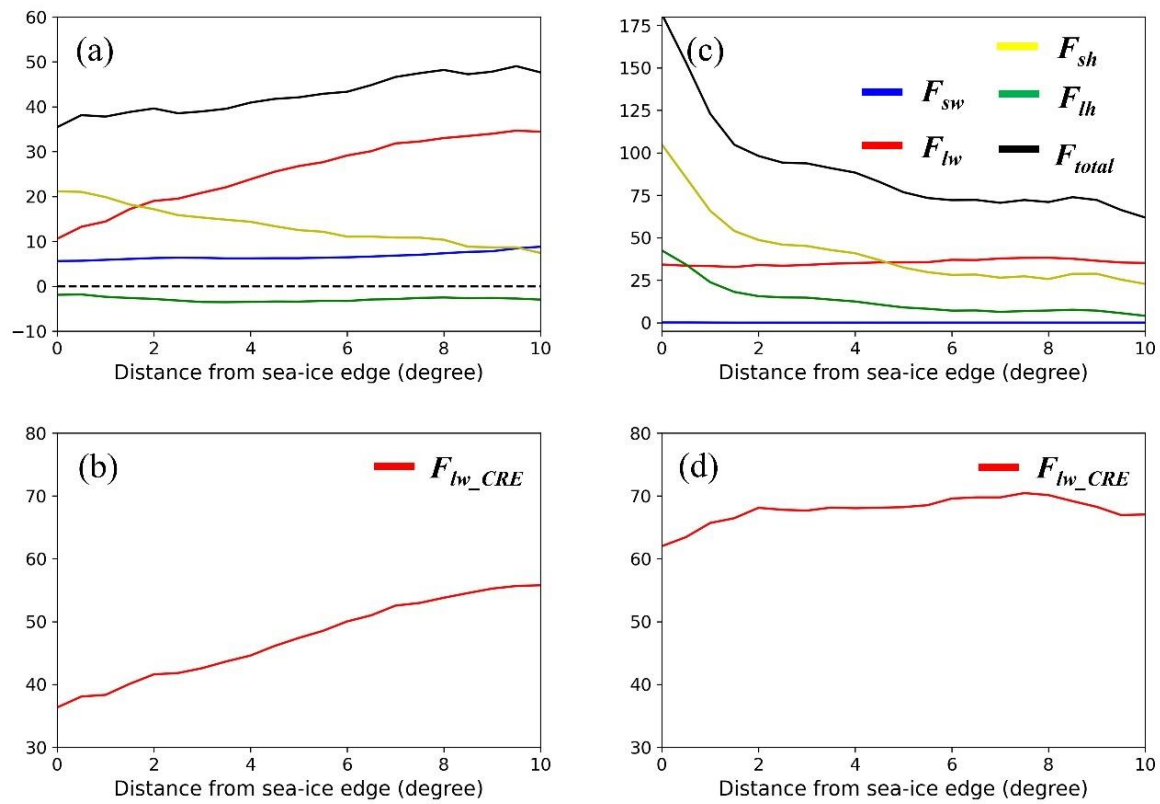

Figure 10. Plots showing the average meridional change in the anomalies of (a) the sum $\left(F_{\text {total }}\right.$,

$519 \mathrm{~W} \mathrm{~m}^{-2}$; black) and individual surface fluxes of sensible heat $\left(F_{s h}, \mathrm{~W} \mathrm{~m}^{-2}\right.$; yellow $)$, latent heat $\left(F_{l h}, \mathrm{~W}\right.$ $520 \mathrm{~m}^{-2}$; green $)$, net longwave irradiance $\left(F_{l w}, \mathrm{~W} \mathrm{~m}^{-2} ;\right.$ red $)$ and net shortwave irradiance $\left(F_{s w}, \mathrm{~W} \mathrm{~m}{ }^{-2}\right.$;

521 blue) along the trajectories. (b) shows the cloud radiative effect by longwave $\left(F_{l w_{-} C R E}\right.$; red). (c)(d) are the counterparts of (a)(b) over the frozen seas. 
(a) clwc $\left(\mathrm{g} \mathrm{kg}^{-1}\right)$

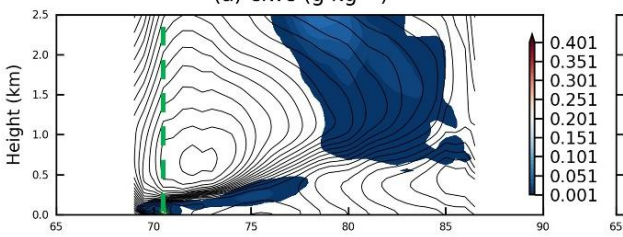

(c) Temperature (K)

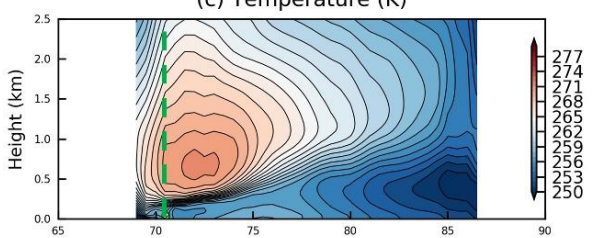

(e) T_tendency $\left(K\right.$ day $\left.^{-1}\right)$

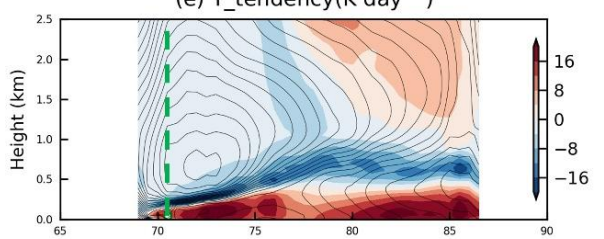

(g) Latent Heating $\left(\mathrm{K} \mathrm{day}^{-1}\right)$

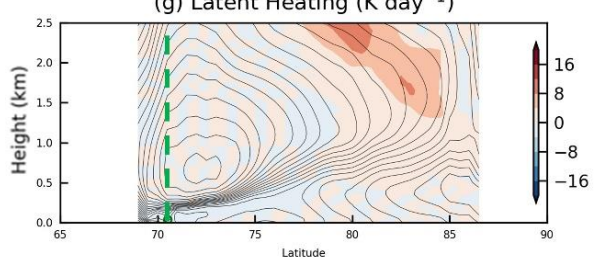

(b) Potential Temperature (K)

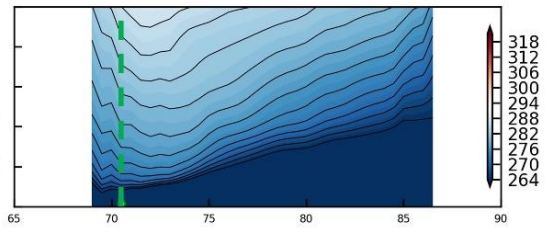

(d) Specific Humuidity $\left(\mathrm{g} \mathrm{kg}^{-1}\right)$

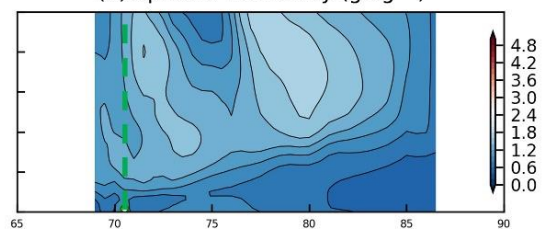

(f) Longwave Radiative Heating ( $\mathrm{Kday}^{-1}$ )

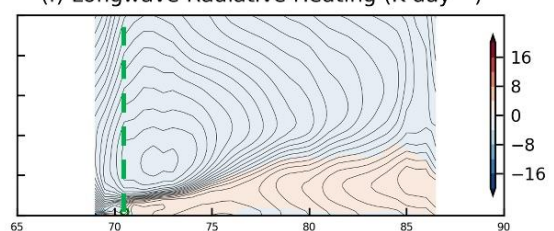

(h) Turbulent Sensible $\&$ Latent Heat $\left(K\right.$ day $\left.^{-1}\right)$

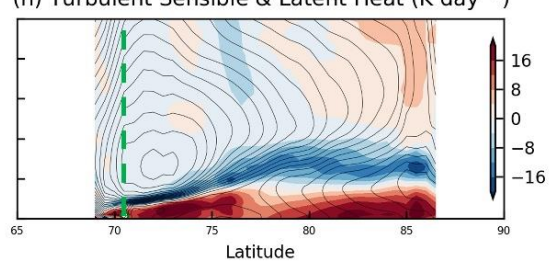

Figure 11. Latitude-height cross-section of (a) cloud liquid water concentration $\left(\mathrm{g} \mathrm{kg}^{-1}\right)$, (b) potential temperature $(\mathrm{K}),(\mathrm{c})$ temperature $(\mathrm{K})$, (d) specific humidity $\left(\mathrm{g} \mathrm{kg}^{-1}\right),(\mathrm{e})$ temperature tendency due to model physics $\left(\mathrm{K} \mathrm{day}^{-1}\right)$, (f) longwave radiative heating $\left(\mathrm{K} \mathrm{day}^{-1}\right)$, (g) latent heating $(\mathrm{K}$ day $^{-1}$ ) and $(\mathrm{h})$ turbulent heating $\left(\mathrm{K} \mathrm{day}^{-1}\right)$, interpolated from ERA5 along trajectories of one selected WaMAI from category INV. The green dash lines mark the location of ice-edge. See the text for a detailed discussion. 
https://doi.org/10.5194/acp-2021-610

Preprint. Discussion started: 17 August 2021

(c) Author(s) 2021. CC BY 4.0 License.

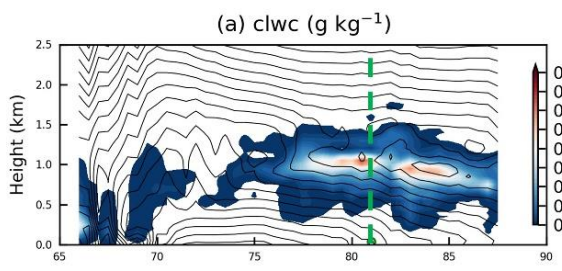

(c) Temperature (K)

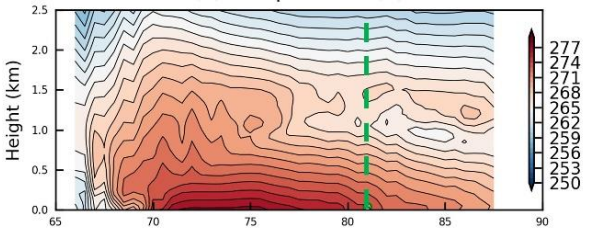

(e) T_tendency $\left(\mathrm{Kday}^{-1}\right)$

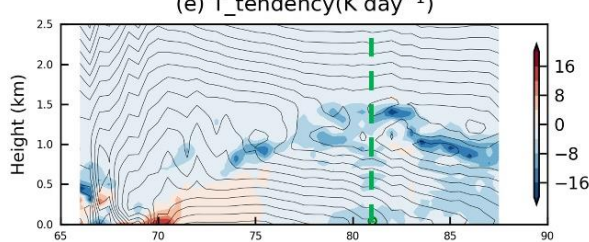

(g) Latent Heating $\left(\mathrm{K} \mathrm{day}^{-1}\right)$

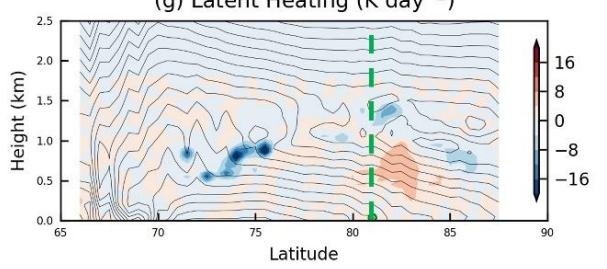

(b) Potential Temperature (K)

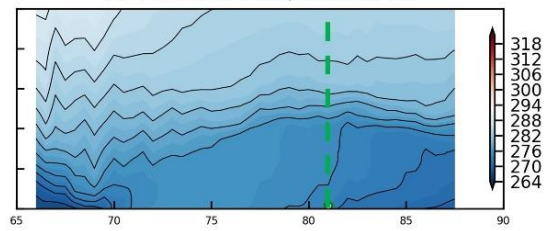

(d) Specific Humuidity $\left(\mathrm{g} \mathrm{kg}^{-1}\right)$

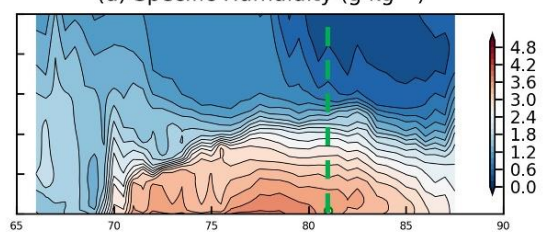

(f) Longwave Radiative Heating ( $\mathrm{K} \mathrm{day}^{-1}$ )

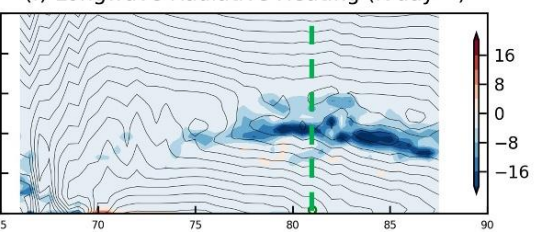

(h) Turbulent Sensible $\&$ Latent Heat $\left({\mathrm{K} d a \mathrm{y}^{-1}}^{-1}\right)$

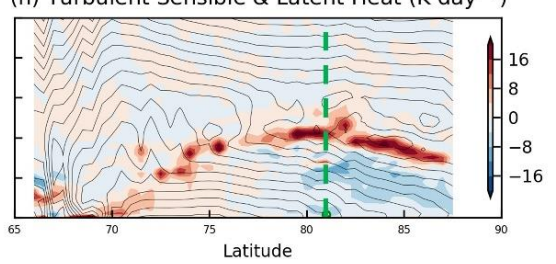

540 Figure 12. Same as figure 13 but for a selected radiation-dominated WaMAI. 


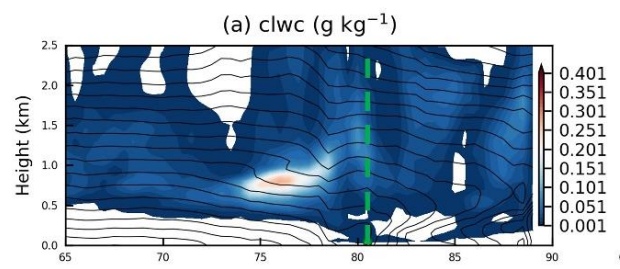

(c) Temperature (K)

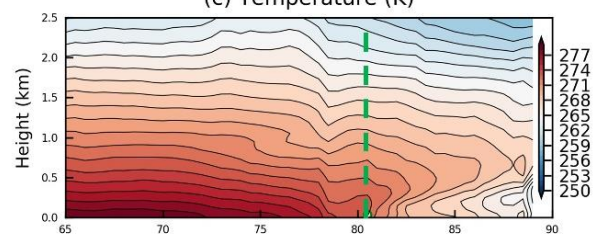

(e) T_tendency $\left(\mathrm{K}_{\mathrm{day}}{ }^{-1}\right)$

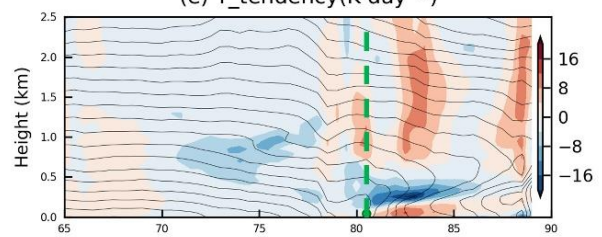

(g) Latent Heating $\left(\mathrm{K}_{\text {day }}{ }^{-1}\right)$

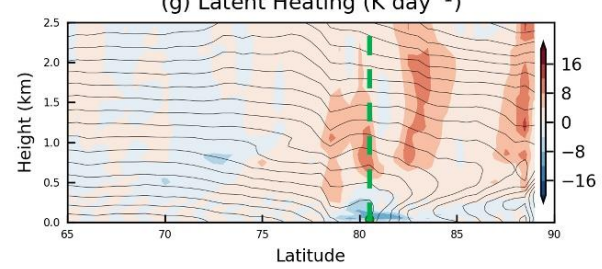

(b) Potential Temperature (K)

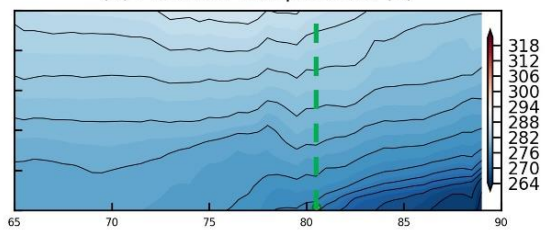

(d) Specific Humuidity $\left(\mathrm{g} \mathrm{kg}^{-1}\right)$

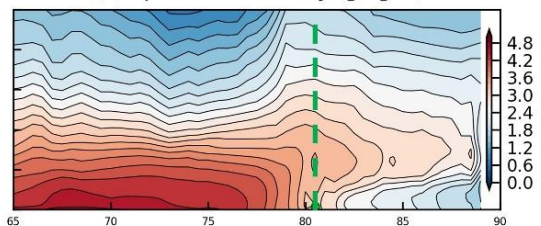

(f) Longwave Radiative Heating $\left(\mathrm{Kday}^{-1}\right)$

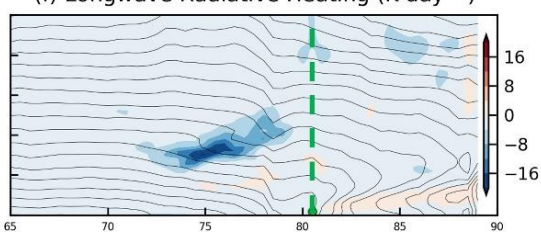

(h) Turbulent Sensible $\&$ Latent Heat $\left(\mathrm{K} \mathrm{day}^{-1}\right)$

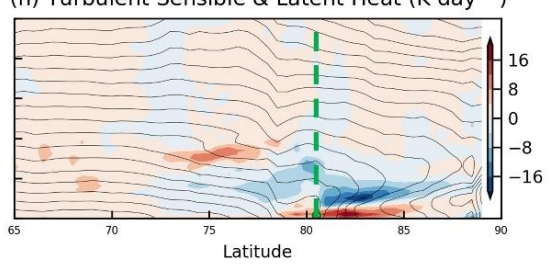

545 Figure 13. Same as figure 10 but for a selected turbulence-dominated WaMAI. 
https://doi.org/10.5194/acp-2021-610

Preprint. Discussion started: 17 August 2021

(c) Author(s) 2021. CC BY 4.0 License.

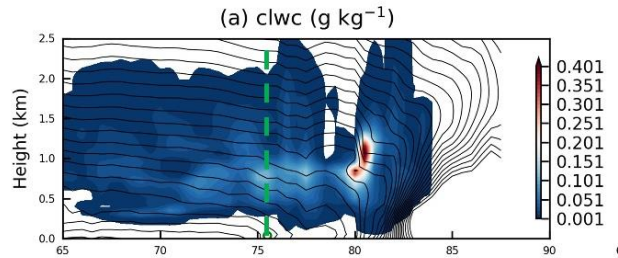

(c) Temperature (K)

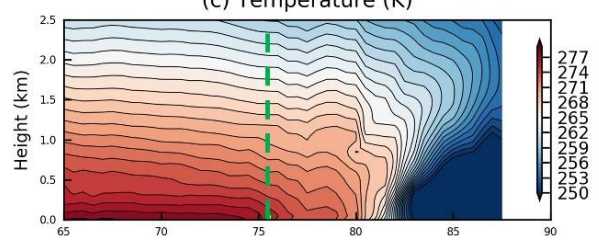

(e) T_tendency $\left(\mathrm{K}_{\text {day }}{ }^{-1}\right)$

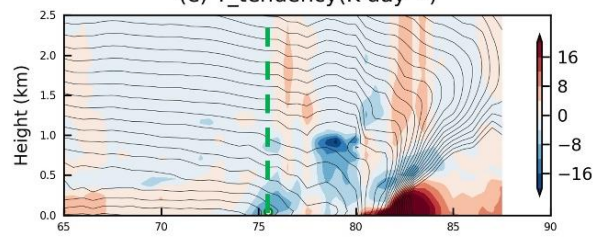

(g) Latent Heating $\left(\mathrm{Kday}^{-1}\right)$

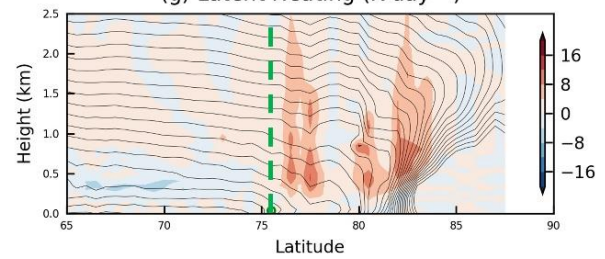

(b) Potential Temperature (K)

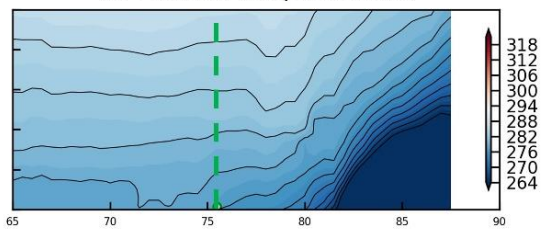

(d) Specific Humuidity $\left(\mathrm{g} \mathrm{kg}^{-1}\right)$

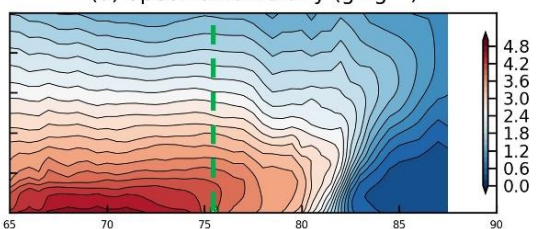

(f) Longwave Radiative Heating ( $\left.\mathrm{Kday}^{-1}\right)$

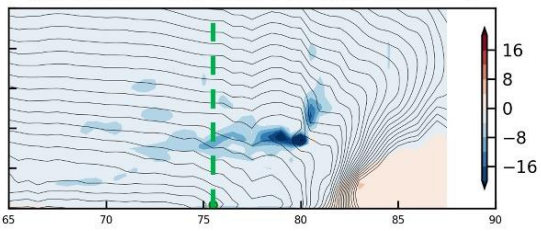

(h) Turbulent Sensible \& Latent Heat $\left(\mathrm{K}_{\text {day }}{ }^{-1}\right)$

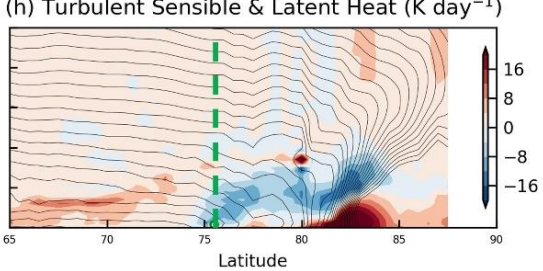

549 Figure 14. Same as figure 10 but for a selected turbulence-dominated WaMAI with cold 550 dome. 
(a)

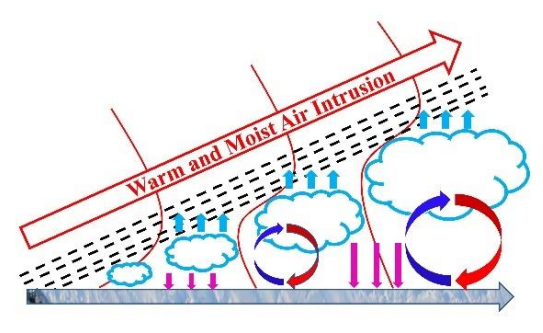

(c)

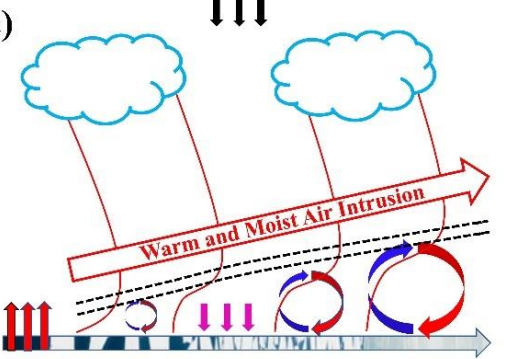

Air-mass heated by

the warm sea surface (b) $\uparrow \uparrow \uparrow \quad \uparrow \uparrow \uparrow \quad \uparrow \uparrow \uparrow$

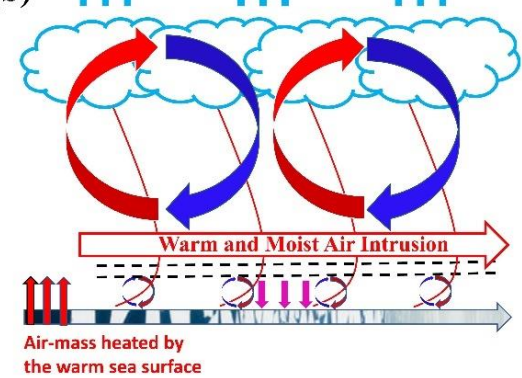

(d)

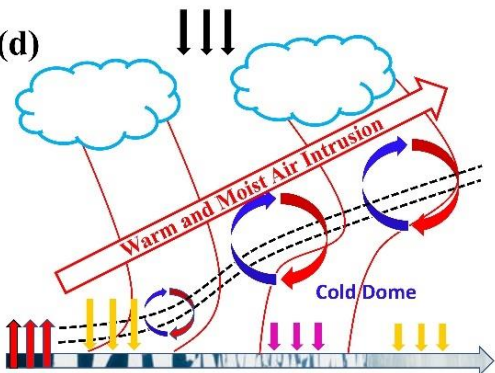

Air-mass heated by

the warm sea surface
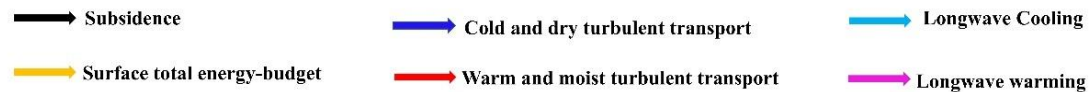

552

553

554

555

556

557

558

559

560

561

562

563

564

565

566

Figure 15. Concept graph of WaMAI from category (a) INV, (b) radiation-dominated WaMAI, (c) turbulence-dominated WaMAI, (d) turbulence-dominated WaMAI with cold dome. The red lines in (a)(b)(c) are temperature or humidity profiles. Red arrows represent the WaMAIs. The horizontal arrows represent the Arctic surface with frozen or melting seaice. Black lines represent inversions. 

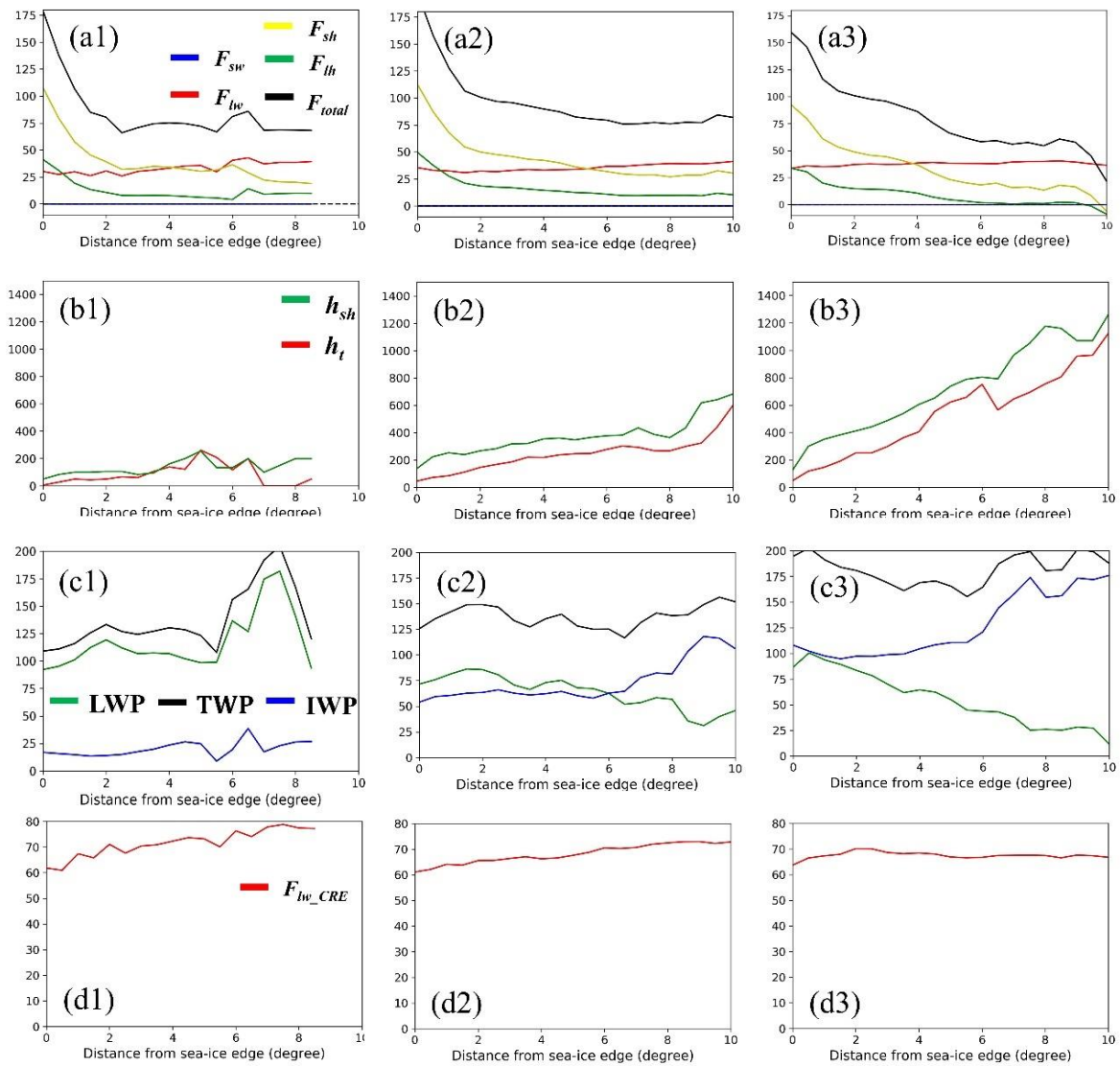

Figure 16. Average variation of (a1) the sum $\left(F_{\text {total }}, \mathrm{W} \mathrm{m}^{-2}\right.$; black) and individual surface fluxes of sensible heat $\left(F_{s h}, \mathrm{~W} \mathrm{~m}^{-2}\right.$; yellow), latent heat $\left(F_{l h}, \mathrm{~W} \mathrm{~m}^{-2}\right.$; green), net longwave irradiance $\left(F_{l w}, \mathrm{~W} \mathrm{~m}{ }^{-2}\right.$; red) and net shortwave irradiance $\left(F_{s w}, \mathrm{~W} \mathrm{~m}^{-2}\right.$; blue); (b1) the height to the maximum specific humidity $\left(h_{s h}\right)$ and temperature $\left(h_{t}\right)$; (c1) liquid water path (LWP; $\mathrm{g} \mathrm{m}^{-2}$ ), ice water path (IWP; $\mathrm{g} \mathrm{m}^{-2}$ ) and total water path (TWP; $\mathrm{g} \mathrm{m}^{-2}$ ); (d1) the cloud radiative effect by longwave $\left(F_{l w_{-} C R E} ;\right.$ red), with the downstream northward distance from sea-ice edge, along the trajectory of WaMAI in category of RAD over the Barents Sea. (a2)(b2)(c2)(d2) $((\mathrm{a} 3)(\mathrm{b} 3)(\mathrm{c} 3)(\mathrm{d} 3))$ are the same but for WaMAIs in category of TBL (TCD). 